\title{
¿TOMANDO LA JUSTICIA CAUTELAR EN SERIO?: LAS MEDIDAS PROVISIONALES EN LA JURISPRUDENCIA DEL TRIBUNAL EUROPEO DE DERECHOS HUMANOS
}

\author{
MARÍA DÍAZ CREGO \\ Profesora Titular de Derecho Constitucional \\ Universidad de Alcalá
}

\begin{abstract}
SUMARIO
I. Introducción. II. Comencemos con el cumplimiento: sobre la vinculatoriedad de las medidas cautelares y el alcance de las obligaciones que asumen los Estados. III. Algunas cuestiones procedimentales: un análisis especialmente diligente del riesgo. IV. Los criterios a considerar en el juicio cautelar: riesgo real e inminente y daño grave e irreparable. V. Conclusiones.
\end{abstract}

\section{INTRODUCCIÓN}

La tutela cautelar de los derechos reconocidos en el Convenio Europeo de Derechos Humanos (CEDH o Convenio, en adelante) se ha convertido en los últimos años en uno de los buques insignia del sistema europeo de protección de los derechos fundamentales, ofreciendo al Tribunal Europeo de Derechos Humanos (TEDH o Tribunal, en adelante) una oportunidad más de demostrar su voluntad de garantizar derechos reales y efectivos.

Téngase en cuenta que la justicia cautelar tiene como finalidad esencial preservar la integridad del proceso, previniendo que los avatares del mismo o el mero transcurso del tiempo impidan desarrollar todos sus efectos a la resolución judicial que le ponga fin. Las medidas cautelares preservarán los derechos de las partes a la espera de la resolución judicial definitiva, garantizando su eficacia y evitando que su cumplimiento se vea comprometido ${ }^{1}$.

1 En este sentido, ver: WhatThée, S., Les mesures provisoires devant la Cour européenne des droits de l'homme: La protection préventive des droits conventionnels en puissance?. Bruselas, Anthemis, 2017, p. 31 y ss.; Cameron, A.M., Provisional Measures before International Courts and Tribunals, Cambridge Studies in International and Comparative Law, Nueva York, 2017, págs 1 y ss.; Chinchilla, C., La tutela cautelar en la nueva justicia administrativa, Madrid, Civitas, 1991. 
En el marco de los procesos dirigidos a tutelar derechos fundamentales, a la finalidad genérica de toda medida cautelar, se añade un elemento clave vinculado a la mayor trascendencia del contenido de los derechos de las partes que se pretenden salvaguardar. No se trata sólo de garantizar la efectividad de la resolución judicial definitiva, sino de preservar los derechos fundamentales de la parte evitando toda situación que pueda devenir irreversible ${ }^{2}$. El TEDH lo indica en su jurisprudencia con total claridad: sus medidas cautelares persiguen salvaguardar los derechos de las partes, evitando situaciones irreversibles que impedirían al tribunal examinar debidamente la demanda y garantizar el cumplimiento de la eventual resolución de fondo ${ }^{3}$.

A pesar de la trascendencia que tiene la tutela cautelar para garantizar la efectividad de los litigios en materia de derechos fundamentales y que el TEDH reconoce como fundamento de su jurisprudencia en la materia, llama poderosamente la atención que el $\mathrm{CEDH}$ no haga referencia alguna a la posibilidad de que sus órganos de control adopten este tipo de medidas. El sistema europeo se distingue así, tal y como se ha subrayado en múltiples ocasiones ${ }^{4}$, del otro gran sistema regional de protección de los derechos humanos, en la medida en que el art. 63.1 de la Convención Americana de Derechos Humanos, sí recoge de forma expresa la competencia de la Corte Interamericana para adoptar medidas provisionales.

No obstante, haciendo uso de unas mimbres normativas muchos menos sólidas, la jurisprudencia del TEDH ha convertido sus medidas cautelares en obligatorias para los Estados parte. Ese elemento, y la diligencia con que la institución analiza toda petición al efecto, parecen haber dado alas a quienes acuden a Estrasburgo buscando un remedio inmediato a una vulneración de sus derechos fundamentales que no hallan en su ordenamiento nacional.

No es de extrañar así que, en años posteriores al primer pronunciamiento europeo que declaraba la obligatoriedad de las medidas cautelares adoptadas por el $\mathrm{TEDH}^{5}$, se produjera un incremento notable del número de solicitudes de medidas cautelares presentadas ante Estrasburgo, con picos especialmente altos en 2008 y $2010^{6}$, el último de los cuales llevó al propio Presidente del TEDH a emitir un comunicado en el manifestaba

2 Whatthée, S., op. cit., p.. 33 y ss.; Burgorgue- LARSEN, L., «Interim measures in the European system of Human Rights», Inter-American and European Human Rights Journal, vol.2, n. ${ }^{\circ} 1-2,2009$, p. 99.

3 Entre muchas otras, STEDH Toumi c. Italia, de 5 de abril de 2011, § 70; Ben Khemais c. Italia, de 24 de febrero de 2009, $\$ 82$.

4 Entre otros, Burbano Herrera, C. - Haeck, Y., «Letting States of the hook? The paradox of the legal consequences following state non-compliance with provisional measures in the Inter-American and European Human Rights Systems». Netherlands Quaterly of Human Rights, vol. 28/3, 2010, p. 334 y ss.; PasQualucCI, J. M., «Interim measures in international human rights: evolution and harmonization». Vanderbilt Journal of Transnational Law, vol. 38, n. ${ }^{\circ} 1,2005$, p.. 6 y ss.

5 STEDH Mamatkulov y Askarov c. Turquía, Gran Sala, de 4 de febrero de 2005, que se comentará en el apartado siguiente.

6 En 2008, se solicitaron un total de 3185 medidas cautelares, de las cuales tan sólo 747 fueron concedidas. En 2010, el número de solicitudes ascendió a 3775, concediéndose 1443 medidas cautelares. La información se ha tomado de: Council of Europe, Steering Committee for Human Rights, Report on interim measures under Rule 39 of the Rules of Court, de 22 de marzo de 2013 (accesible en file://Users/mariadiaz/Downloads/Compilation\%20ReformECHR2014_en.pdf). Hasta el año 2009, resultan también muy esclarecedores los datos comparados por años que ofrece el trabajo: Burbano Herrera, C., «A Critical Analysis of The Work Of The European Commission And European Court Of Human Rights In Relation With Non-Compliance Of Interim Measures - Period 1957 $2011 »$. Revista Via Inveniendi Et Iudicandi , 7 (2), 2012, p. 22. 
su preocupación por un aumento que cuantificaba en un $4000 \%$ entre 2006 y 2010 y que impedía al TEDH desarrollar su actividad con garantías ${ }^{7}$. En años ulteriores, el número de solicitudes parece haberse estabilizado, oscilando entre las 1500-2000 anualmente ${ }^{8}$. Algo semejante ha ocurrido con el porcentaje de solicitudes concedidas, que llegó a alcanzar tasas del $39,1 \%$ en 2010 , pero que parece ubicarse en los últimos años por debajo del $10 \% 9$. Si el número de solicitudes y de concesiones de medidas cautelares ha disminuido desde 2010, lo que parece haber aumentado, aún sin ser todavía preocupante, es el número de casos en que el TEDH confirma que el Estado demandado no ha cumplido la medida cautelar que había sido adoptada. En este sentido, algunos estudios apuntan hacia un incremento de los incumplimientos, señalando que entre 1957 y 2005 , apenas se produjeron una decena ${ }^{10}$, ascendiendo la cifra a más de 40 desde el año 2005 hasta la fecha ${ }^{11}$.

Dado que la tutela cautelar es esencial para garantizar la efectividad de la labor que desarrolla el TEDH y que sólo conseguirá su finalidad última si las medidas se adoptan de forma ágil, para evitar situaciones irreparables, y los Estados aceptan su cumplimiento, parece claro que el Tribunal debe prestar particular atención a la determinación de las obligaciones que incumben a los Estados respecto de sus medidas cautelares, al procedimiento que sigue para el tratamiento de estas solicitudes, y a la definición de los elementos que le llevan a adoptar o denegar las medidas cautelares que se solicitan. Este trabajo pretende abordar esos tres elementos clave, buscando una suerte de evaluación de la práctica del TEDH en la materia.

7 ECHR, «Governments, applicants and their lawyers urged to co-operate fully with European Court, following «alarming rise» in requests to suspend deportation», Statment made by the President Jean-Paul Costa, Press Release n. ${ }^{\circ}$ 17, 11 de febrero de 2011.

8 En este sentido, ver las últimas estadísticas proporcionadas por el TEDH, en las que se indica que, en 2015 se recibieron un total de 1458 solicitudes, en 2016, un total de 2286, y en 2017, un total de 1669. La información completa puede encontrarse en: ECHR, «Rule 39 requests granted and refused in 2015, 2016 and 2017 by respondent state», accesible en https://www.echr.coe.int/Documents/Stats_art_39_01_ENG.pdf

9 Así se desprende de los datos proporcionados por el propio TEDH en sus Informes anuales y en las estadísticas proporcionadas en su página web. Teniendo en cuenta los datos que se facilitan en el documento citado supra, en 2015 el número de solitudes concedidas habría sido del 11\%, en 2016, del 5\%, y en 2017, del 7\%. Llama la atención que ese descenso se haya producido tras la Declaración de Izmir, adoptada por la Conferencia de Alto Nivel sobre el Futuro del TEDH, el 27 de abril de 2011, y en la que se instaba al TEDH a reducir el número de solicitudes concedidas con las siguientes palabras: «As regards Rule 39, expresses its expectation that the implementation of the approach set out in paragraph A3 will lead to a significant reduction in the number of interim measures granted by the Court, and to the speedy resolution of those applications in which they are, exceptionally, applied, with progress achieved within one year. The Committee of Ministers is invited to revert to the question in one year's time» (Follow-up Plan (Implementation), par. 4).

10 Para un análisis del número y alcance de los incumplimientos desde 1957 hasta el año 2010, ver especialmente Burbano Herrera, C., op. cit.

11 Una lista completa de los incumplimientos desde 2005 hasta 2014 puede encontrarse en: PACE, Committee on Legal Affairs and Human Rights, «Report on the Urgent need to deal with new failures to co-operate with the European Court of Human Rights», Doc. 13435, de 28 de febrero de 2014. A la lista de casos de incumplimiento citados en ese informe (31) habría que añadir los siguientes, que no son citados en el informe: SSTEDH Makharadze y Sikharulidze c. Georgia, de 22 de noviembre de 2011; Rrapo c. Albania, de 25 de septiembre de 2012; Salakhov y Islyamova v. Ucrania, de 14 de marzo de 2013; Trabelsi c. Bélgica, de 4 de septiembre de 2014; Amirov c. Rusia, de 27 de noviembre de 2014; Sergey Antonov c. Ucrania, de 22 de octubre de 2015; Andrey Lavrov c. Rusia, de 1 de marzo de 2016; Klimov c. Rusia, de 4 de octubre de 2016; Maylenskiy c. Rusia, de 4 de octubre de 2016; Pivovarnik c. Ucrania, de 6 de octubre de 2016; Konovalchuk c. Ucrania, de 13 de octubre de 2016; M.A. c. Francia, de 1 de febrero de 2018; y A.S. c. Francia, de 19 de abril de 2018. 


\section{COMENCEMOS CON EL CUMPLIMIENTO: SOBRE LA VINCULATORIEDAD DE LAS MEDIDAS CAUTELARES Y EL ALCANCE DE LAS OBLIGACIONES QUE ASUMEN LOS ESTADOS}

Quizás por la ausencia de referencia convencional expresa a la facultad del TEDH, o de la desaparecida Comisión Europea de Derechos Humanos, de adoptar medidas cautelares, el TEDH no reconoció su carácter vinculante sino hasta el ya famoso caso Mamatkulov y Askarov c. Turquía, Gran Sala, de 4 de febrero de 2005. Desde entonces su jurisprudencia al respecto se ha ido perfilando, estrechando cada vez más los márgenes de actuación de los Estados parte en la materia. Tenemos hoy perfectamente claro que las medidas cautelares del TEDH son obligatorias y que cualquier incumplimiento provoca la automática vulneración del art. $34 \mathrm{CEDH}$. Más allá de esa precisión, la jurisprudencia del TEDH mira con lupa cualquier cumplimiento tardío o parcial, así como los intentos de los Estados de justificar su incumplimiento aduciendo motivaciones variopintas. Veamos con detalle la jurisprudencia del TEDH al respecto.

\section{Refrescando la memoria: de la ausencia de base convencional a la vinculatoriedad de las medidas cautelares adoptadas por el TEDH}

Como ya he señalado, el CEDH no hace referencia expresa a la facultad de sus órganos de control de adoptar medidas cautelares. Tal y como ha explicado prolijamente What thée, los trabajos preparatorios del Convenio no recogen ninguna mención relacionada con la atribución de esa facultad a sus órganos de control, pareciendo - de forma un tanto sorprendente- que esa cuestión no fue objeto de debate alguno en el momento en que se redactó el Convenio ${ }^{12}$.

Tan sólo años después, en 1971, la Asamblea Parlamentaria dirigiría una recomendación al Comité de Ministros para que encargara al Comité de Expertos en materia de derechos humanos la redacción de un Protocolo adicional al CEDH que atribuyera tal competencia a los órganos de control del CEDH y, en especial, a la Comisión Europea ${ }^{13}$. El Comité de expertos estimó que, dado que la práctica de la Comisión Europea en materia de medidas cautelares era satisfactoria, no parecía conveniente adoptar un Protocolo adicional que regulara el procedimiento y los criterios para la indicación de tales medidas ${ }^{14}$.

El Comité de Ministros asumió tal posicionamiento, subrayando la existencia de una laguna en la materia, pero señalando que la formalización de la facultad de los

12 WhatThÉe, S., op. cit., págs 65 y ss. La autora señala que esa ausencia de debate parece tanto más sorprendente si se tiene en cuenta que el Movimiento Europeo remitió al Consejo de Ministros un proyecto de Estatuto que sí contenía un precepto referido a la tutela cautelar. Ver, Preparatory Commission of the Council of Europe, Committee of Ministers, Consultative Assembly (11 May - 8 September 1949). La Haya, Martinus Nijhoff, 1975, vol. 1, p. 315 .

13 Asamblea Parlamentaria, Recomendación 623 (1971), de 21 de enero de 1971, relative aux mesures provisoires complementaires à la Convention Européenne des Droits de l'Homme.

14 Comité de Ministros, Conclusiones de la 224. ${ }^{a}$ reunión de delegados, 18-26 septiembre 1973, Mesures provisoires complementaires à la Convention Européenne des Droits de l'Homme. Rapport du Comité d'expert en matière de droits de l'homme. Doc. CM (73) 57 (accesible en https://rm.coe.int/0900001680521a78) 
órganos de Estrasburgo de adoptar medidas cautelares a través de un Protocolo adicional y la correspondiente introducción de obligaciones jurídicas podía poner en riesgo la práctica desarrollada por la Comisión Europea durante años ${ }^{15}$. Se explicaba así, negro sobre blanco, que las recomendaciones de la Comisión Europea en la materia —el TEDH todavía no había tenido oportunidad de aplicar el entonces art. 34 de su Reglamento interno — no eran más que eso «recomendaciones» y que, por tanto, no parecía deducirse obligación jurídica alguna para los Estados. Con estos argumentos, que trasladaban la escasa voluntad de los Estados de formalizar lo que se describía como una exitosa "práctica», se abandonó la idea de dotar de base convencional a la adopción de medidas cautelares por los órganos de control del Convenio.

Esa idea no volvió a recuperarse ni siquiera al hilo de la elaboración de los Protocolos núm. 11 y 14, que introdujeron notables novedades en el sistema de control del Convenio, a pesar de que varios actores, inclusive el propio $\mathrm{TEDH}^{16}$, plantearon la necesidad de introducir una cláusula convencional al respecto. No obstante, la cuestión sí parece haberse planteado en los debates más recientes sobre el futuro del $\mathrm{CEDH}^{17}$, pero sin que las propuestas realizadas se hayan materializado por el momento.

De esta suerte, la práctica de ambas instituciones en relación con la adopción de medidas cautelares se ha fundado siempre en las previsiones de sus propios Reglamentos internos. Como explican Burbano y Haeck ${ }^{18}$, el TEDH fue el primero en introducir en su Reglamento interno (art. 34) una previsión que le permitía llamar la atención de los Estados parte sobre las medidas cautelares que considerara deseable adoptar, al incluir tal posibilidad en su Reglamento de $1959^{19}$.

Por su parte, la Comisión Europea tardó mucho más en incluir tal previsión en su Reglamento interno ${ }^{20}$. Habría que esperar a la reforma del Reglamento de 1974 , ulterior a la decisión del Comité de Ministros de no elaborar un Protocolo adicional en la materia $^{21}$, para que expresamente se atribuyera a la Comisión o, cuando no estuviera en sesión, a su Presidente, la facultad de indicar a los Estados las medidas provisionales consideradas deseables en interés de las partes o del correcto desarrollo del proceso (art. 36) ${ }^{22}$. A

15 Comité de Ministros, Conclusiones de la 224. ${ }^{a}$ reunión de delegados, 18-26 septiembre 1973, Mesures provisoires complementaires à la Convention Européenne des Droits de l'Homme. Rapport du Comité d'expert en matière de droits de l'homme. Concl (71) 199, point III B (h) (accesible en https://rm.coe.int/0900001680521a78)

16 Opinion of the Court on Draft Protocol No. 11 to the European Convention on Human Rights, Doc. DH-PR (94)4, 31 de enero de 1994.

17 Ver, especialmente, Council of Europe, Steering Committee For Human Rights, Final report on a simplified procedure for amendment of certain provisions of the Convention, 22 de junio de 2012.

18 Para un análisis más detallado, ver: Burbano Herrera, C. y Haeck, Y., op. cit., p. 339 y ss.

19 El texto original en inglés versa: «1. Before the constitution of a Chamber, the President of the Plenary Court may, at the request of a Party, the Commission, or any person concerned or propio motu, bring to the attention of the Parties any interim measure the adoption of which seems desirable. The Chamber, when constituted, or, if the Chamber is not on session, its President, shall have the same right. 2. Notice of these measures shall be immediately given to the Committee of the Ministers.» (Rule 34, accesible en https://www.echr.coe.int/Documents/ Library_1959_RoC_CDH(59)8_ENG.PDF)

20 La primera versión del Reglamento interno de la Comisión se aprueba el 2 de abril de 1955 y no hace referencia alguna a la posibilidad de indicar medidas cautelares (accesible en https://www.echr.coe.int/Documents/ Archives_1955_Rules_Commission_BIL.pdf)

21 Whatthée, S., op. cit., p. 67 y ss.

22 En relación con esta modificación, ver: Burbano y Haeck, op. cit, p. 338. El texto original en inglés versaba: «The Commission or, where it is not in session, the President may indicate to the parties any interim measure 
pesar de ello y de forma un tanto llamativa, en el momento en que se introduce tal posibilidad de forma expresa en su Reglamento, la Comisión Europea llevaba ya años recomendado informalmente a los Estados parte la adopción de medidas cautelares, datando la primera de ellas de $1957^{23}$. Por su parte, el TEDH no adoptó ninguna medida cautelar hasta el famoso caso Soering c. Reino Unido, de 7 de julio de 1989, en el que prorrogó la indicada previamente por la Comisión Europea ${ }^{24}$.

Por lo que aquí interesa, el texto inicial del Reglamento interno del TEDH no sufrió modificaciones sustanciales en lo referido a la facultad del tribunal de indicar medidas cautelares a los Estados hasta $1998^{25}$, momento en que se produce la adaptación del Reglamento al Protocolo núm. 11, el artículo referido a las medidas cautelares pasa a ser el número 39 y el texto del mismo se moldea a la luz de lo que preveía el Reglamento interno de la Comisión, recogiéndose expresamente que el TEDH podría indicar las medidas cautelares que considerara apropiadas en interés de las partes o del correcto desarrollo del proceso, y podría requerir a las partes información referida a la implementación de tales medidas ${ }^{26}$. Tras esta modificación, el resto de las sufridas por el precepto tienen que ver con la notificación de las medidas cautelares indicadas al Comité de Ministros ${ }^{27}$ o con el órgano competente para la adopción de las mismas ${ }^{28}$.

the adoption of which seems desirable in the interest of the parties or the proper conduct of the proceedings before it» (Rule 36).

23 En este sentido, ver: Burbano y Haeck, op. cit, p. 337.

24 En este sentido, ver: Burbano y Haeck, op. cit, p. 339.

25 En el nuevo Reglamento interno del TEDH, adoptado el 24 de noviembre de 1982 , el artículo 34 pasa a ser el 36, introduciéndose una modificación sutil, en la medida en que el texto recoge la facultad del TEDH de indicar/recomendar a los Estados la adopción de medidas cautelares. El texto original en inglés recoge, tras la reforma: «1. Before the constitution of a Chamber, the President of the Court may, at the request of a Party, the Commission, or any person concerned or propio motu, indicate to Parties any interim measure which is advisable for them to adopt. The Chamber, when constituted, or, if the Chamber is not on session, its President, shall have the same right. 2. Notice of these measures shall be immediately given to the Committee of the Ministers. "(Rule 36, accesible en https://www.echr.coe.int/Documents/Library_1982_RoC_Revised_Nouveau_BIL.PDF). Desde una perspectiva jurídica, la diferencia parece escasa, en la medida en que la nueva redacción no estaba llamada a convertir las medidas cautelares en vinculantes para los Estados. El art. 36 de ese nuevo reglamento sufre varias modificaciones: el 26 de enero de 1989, a fin de contemplar la posibilidad de que el TEDH mantuviera las medidas cautelares indicadas por la Comisión (accesible enhttps://www.echr.coe.int/Documents/Library_1989_RoC_BIL.PDF) y el 20 de abril de 1992, a fin de contemplar la posibilidad de que el TEDH indicara medidas cautelares también al demandante (accesible en https://www.echr.coe.int/Documents/Library_1992_RoC_BIL.PDF). Ese mismo texto pasó a convertirse en el art. 38 del Reglamento interno con la modificación que entró en vigor el 23 de mayo de 1996 (https://www.echr. coe.int/Documents/Library_1996_RoC_Part\%20B_BIL.PDF)

$26 \mathrm{El}$ texto en inglés versa: 1. The Chamber or, where appropriate, its President may, at the request of a party or of any other person concerned, or of their own motion, indicate to the parties any interim measure which it considers should be adopted in the interests of the parties or of the proper conduct of the proceedings before it. 2 . Notice of these measures should be given to the Committee of Ministers. 3. The Chamber may request information from the parties on any matter connected with the implementation of any interim measure it has indicated (Rule 39, accesible en https://www.echr.coe.int/Documents/Library_1998_RoC_BIL.pdf)

27 La modificación introducida el 1 de septiembre de 2012 dejaba en manos del TEDH la decisión de notificar la adopción de medidas cautelares al Comité de Ministros, cuando se considerara apropiado: «2. Where it is considered appropriate, immediate notice of the measure adopted in a particular case may be given to the Committee of Ministers.» (Rule 39, accesible en https://www.echr.coe.int/Documents/Library_2012_RoC_Sep_ENG.PDF)

28 La modificación introducida el 1 de junio de 2015 atribuía la competencia para adoptar medidas cautelares no sólo a la Sala o a los Presidentes de Sección, sino también a los Vicepresidentes de Sección que fueran designados para ello, en línea con la redacción actual del art. 39 del Reglamento interno del TEDH (la versión de 2015 es accesible en https://www.echr.coe.int/Documents/Library_2015_RoC_ENG.PDF). 
Teniendo en cuenta la redacción dada al actual art. 39 del Reglamento interno del TEDH - y al anterior art. 36 del Reglamento de la Comisión-, así como la justificación de la negativa del Comité de Ministros a adoptar un Protocolo adicional que dotara de base jurídica convencional a la adopción de medidas cautelares por los órganos de control del Convenio, parece lógico que el TEDH haya tenido una posición titubeante en relación con la obligatoriedad de sus medidas cautelares.

Como es bien sabido, en el criticado asunto Cruz Varas y otros c. Suecia, Pleno, de 20 de marzo de 1991, el TEDH se pronunció en contra de la obligatoriedad de las adoptadas por la entonces Comisión Europea ${ }^{29}$. El TEDH trató de justificar su pronunciamiento aludiendo a la inexistencia de base convencional, los fracasados intentos por incluirla, la propia dicción del art. 36 del Reglamento interno de la Comisión — que utilizaba el verbo «indicar» y hablaba del carácter «deseable» de las medidas cautelares adoptadas_-, la ausencia de jurisprudencia internacional que apoyara la tesis de la obligatoriedad de esas medidas, y la imposibilidad de derivar del entonces art. $25 \mathrm{CEDH}-$ derecho a plantear una demanda individual ante la Comisión - una nueva obligación jurídica que se impondría a los Estados.

Tales planteamientos ocultaban difícilmente que el incumplimiento de las medidas cautelares ponía en cuestión la protección real y efectiva de los derechos reconocidos en el CEDH — constantemente reiterada por el TEDH en su jurisprudencia-, así como la efectividad del derecho a presentar una demanda ante la entonces Comisión. Como señalaran las voces discrepantes de los Jueces Cremona, Thór Vilhjálmsson, Walsh, Macdonald, Bernhardt, De Meyer, Martens, Foighel y Morenilla, el derecho procedimental garantizado por el entonces art. $25 \mathrm{CEDH}$ debía necesariamente implicar el correspondiente derecho del demandante a que su caso fuera analizado por los órganos de control del CEDH y a que se protegieran sus derechos si se estimaba su demanda. La facultad de adoptar medidas cautelares vinculantes, entendían esos jueces, se derivaba implícitamente del CEDH, ya que lo contrario podría provocar que los Estados causaran daños irreparables a los demandantes, desposeyendo de todo sentido al propio proceso ante Estrasburgo al convertir en imposible el cumplimiento de la resolución definitiva. En fin, las voces discrepantes enfatizaban el estrecho vínculo existente entre la facultad de adoptar medidas cautelares y la propia función de juzgar, en línea con lo indicado por algunos autores $^{30}$. Pero lejos de adoptar esa posición, el TEDH se conformó con subrayar que el incumplimiento de una medida cautelar podría, en todo caso, agravar la responsabilidad del Estado en relación con las vulneraciones sustantivas de otros derechos reconocidos en el $\mathrm{CEDH}^{31}$. Un pronunciamiento que no parecía ser más que simbólico.

El TEDH mantuvo esa línea jurisprudencial, aplicándola a sus propias medidas cautelares $^{32}$, hasta el conocidísimo asunto Mamatkulov y Askarov c. Turquía, en el que

29 Sobre el asunto Cruz Varas, ver García De Enterría, E., «De la légitimité des mesures provisoires prises par la Commission et la Cour européennes. L'affaire Cruz Varas». Revue Trimestrielle des Droits de l'Homme, vol. 11, 1992, p. 251-280.

30 Entre otros, ver: Keller, H. - MARTi, C., «Interim Relief Compared: Use of Interim Measures by the UN Human Rights Committee and the European Court of Human Rights», Heidelberg Journal of International Law, vol. 73(3), 2013, p. 230.

31 STEDH Cruz Varas y otros c. Suecia, de 2 de marzo de 1991, § 103.

32 En el caso Čonka y Ligue Des Droits De L’homme c. Bélgica, Decisión de admisibilidad de 13 de marzo de 2001, el TEDH había indicado al gobierno belga que no expulsara a los demandantes, un grupo de ciudadanos eslovacos 
modificó de forma radical su jurisprudencia precedente sobre la cuestión. En ese asunto, el TEDH abandonó el argumento centrado en la interpretación literal del CEDH que utilizara en Cruz Varas y justificó su posicionamiento haciendo referencia al objeto y la finalidad del tratado - véase, servir de garantía colectiva de los derechos humanos e imponer obligaciones objetivas a los Estados parte-, y a la necesidad de interpretar el texto teniendo en cuenta los principios generales de Derecho Internacional, así como las condiciones actuales —instrumento vivo-, con el ánimo de garantizar derechos reales y efectivo y no teóricos e ilusorios.

Adoptando esta interpretación evolutiva y finalista, el TEDH subrayó la importancia que había adquirido el derecho al recurso individual en el marco del CEDH (art. 34 $\mathrm{CEDH}$ ), especialmente tras las innovaciones introducidas por el Protocolo núm. 11. El TEDH ligaba así la eficacia de esa garantía procedimental con el respeto de las medidas cautelares acordadas por el tribunal. Tales medidas van dirigidas a evitar situaciones irreversibles; garantizar a los demandantes el disfrute efectivo de los derechos que invocan ante el TEDH; permitir a la Corte analizar de forma efectiva y siguiendo su procedimiento habitual las demandas recibidas; $y$, una vez dictada sentencia, facilitar la labor del Comité de Ministros, encargado de controlar la ejecución de la resolución dictada (art. 46 $\mathrm{CEDH}$ ), y las propias obligaciones asumidas por los Estados parte, obligados a ejecutar tales sentencias. En esa lógica, subrayaba el TEDH, el cumplimiento de sus medidas cautelares se vinculaba a lo previsto en los arts. 1, 34 y 46 CEDH.

Más allá de la justificación del cambio jurisprudencial operado por el TEDH sobre la base de las innovaciones introducidas por el Protocolo núm. 11, llamaba la atención la relevancia que el TEDH otorgaba a los principios generales del Derecho Internacional como criterio hermenéutico que le permitía justificar su nuevo posicionamiento. El TEDH aportaba numerosos ejemplos de jurisdicciones internacionales que habían ya reconocido el carácter obligatorio de sus medidas cautelares basándose en la garantía de los derechos de las partes y la eficacia de su propia función jurisdiccional ${ }^{33}$. Entre ellas, el razonamiento del TEDH parecía fuertemente influenciado por las decisiones adoptadas por la Corte Internacional de Justicia en los casos LaGrand, de 27 de junio de 2001, y Avena y otros ciudadanos mexicanos, de 31 de marzo de $2004^{34}$.

A pesar de la relevancia del cambio jurisprudencial que se produjo en la sentencia Mamatkulov y Askarov y del vínculo claro que se estableció entre las medidas cautelares indicadas por el TEDH y el derecho al recurso individual ante el tribunal, el TEDH no

de etnia gitana hacia ese país, a pesar de lo cual el gobierno procedió a ejecutar la expulsión.

33 El TEDH citaba resoluciones de la Corte Interamericana de Derechos Humanos, del Comité de Derechos Humanos y el Comité contra la Tortura, ambos de Naciones Unidas, o de la Corte Internacional de Justicia. Sobre el valor que el TEDH atribuía a esas decisiones, ver: De Schutter, O., «The binding character of the provisional measures adopted by the European Court of Human Rights». International Law Forum du Droit International, vol. 7, 2005 , p. 19 y ss.

34 Sobre la importancia de la CIJ en el cambio jurisprudencial del TEDH, ver: BURGORGUE — Larsen, L. «Interim measures in the European Convention System of Protection of Human Rights». Inter- American and European Human Rights Journal, vol. 2, num. 1-2, 2010, p. 100 ; Cohen- Jonathan, G., «Sur la force obligatoire des mesures provisoires. L'arrêt de la Grande Chambre de la Cour Européenne du 4 février 2005, Mamatkulov et Askarov c. Turquie». Révue Générale de Droit Internationale Public, vol. 2, 2005, p. 432. Sobre la influencia de la jurisprudencia americana en la materia, ver: Salado Osuna, A. y Corzo Sosa, E., «Las medidas provisionales», en García Roca, J. Fernández Sánchez, J., Santolaya, P. , Canosa Usera, R. (coods), El diálogo entre los sistemas americano y europeo de derechos humanos. Civitas, Cizur Menor, 2012, p. 351 y ss. 
llegó a utilizar el término «vinculante» para referirse a esas medidas ni tampoco aclaró si la inobservancia de las mismas provocaba necesariamente la vulneración del art. 34 CEDH. La primera cuestión fue resuelta de forma clara en el caso Aoulmi c. Francia, de 17 de enero de 2006, en el que el TEDH empleó ese adjetivo por vez primera.

La segunda cuestión tardaría un poco más en quedar resuelta, de modo que tras algunas vacilaciones ${ }^{35}$, criticadas por la doctrina ${ }^{36}$, el TEDH aclararía de forma terminante en Olaechea Cahuas c. España, de 10 de agosto de 2006, que la inobservancia de cualquier medida cautelar provocaba una vulneración del art. $34 \mathrm{CEDH}$, independientemente de que, en un momento posterior, se confirmara que el riesgo que pretendía evitar no se había materializado o que el incumplimiento no había provocado que el demandante no pudiera continuar con el procedimiento ante el tribunal ${ }^{37}$. Para el TEDH, la evaluación del riesgo se produce en un momento concreto y conduce a la adopción de una decisión por su parte. El carácter obligatorio para los Estados del contenido de tal decisión no puede hacerse depender de hechos que necesariamente acaecerán después y que no son conocidos por las partes, ni pueden ser evaluados en el momento de la adopción de la decisión cautelar.

A partir del caso Olaechea Cahuas queda perfectamente claro, en la jurisprudencia del TEDH, que todas las medidas cautelares del tribunal son obligatorias y que su incumplimiento provoca, siempre, una vulneración del art. $34 \mathrm{CEDH}$. A pesar de estas certezas, veremos que el TEDH se ha visto obligado a desarrollar de forma mucho más precisa las obligaciones que se imponen a los Estados parte en relación con sus medidas cautelares.

\section{El cumplimiento de las medidas cautelares: ¿qué obligaciones se imponen a los Estados parte?}

Asumida la vinculatoriedad de las medidas cautelares del TEDH, parecería clara la obligación que asumen los Estados en la materia, véase, cumplir lo indicado por el tribunal. Sin embargo, la cuestión de si se ha producido o no el cumplimiento no siempre ha sido indiscutida, como tampoco la determinación de las eventuales causas que eximirían a los Estados de tal obligación. El tribunal ha lidiado con estas cuestiones en jurisprudencia reciente, en la que parece haber interpretado de forma amplia el contenido de sus medidas cautelares, imponiendo así obligaciones muy exigentes a los Estados, a la par que ha reconocido, de forma muy restrictiva, la posibilidad de que eludan el cumplimiento cuando circunstancias objetivas les impidan hacerlo. Veamos con más detalle ambas cuestiones.

35 Ver, STEDH Chamaïev y otros c. Georgia y Rusia, de 12 de abril de 2005, § 478, en el que el TEDH parecía sugerir que la inobservancia de una medida cautelar sólo provocaría una vulneración del art. 34 CEDH si se obstruía el ejercicio del derecho a presentar una demanda individual ante el TEDH. Se planteaba así si no se produciría tal vulneración en aquellos casos en que la inobservancia de la medida cautelar fuera inocua desde la perspectiva del ejercicio efectivo del derecho reconocido en el art. $34 \mathrm{CEDH}$.

36 Burgorgue - LARSEN, L., op. cit, p. 105.

37 Sobre el alcance de esta sentencia, ver: Haeck, Y., Burbano Herrera, C., ZwaAk, L, «Non- compliance with a provisional measure automatically leads to a violation of the right to individual application...or doesn't it?». European Constitutional Law Review, vol. 4, 2008, p. 41-63. 


\subsection{La obligación de dar cumplimiento a la medida cautelar: el rigor y la celeridad se imponen}

Tal y como ya he apuntado, el TEDH ha impuesto obligaciones muy exigentes a los Estados miembros en lo que al cumplimiento de sus medidas cautelares se refiere. De su jurisprudencia se desprenden claramente varias obligaciones:

a) los Estados no pueden sustituir al propio tribunal en lo que a la valoración del riesgo se refiere;

b) la interpretación del contenido de las medidas cautelares europeas no puede ser formalista;

c) los Estados habrán de cumplir esas medidas con una celeridad y diligencia notable, articulando procedimientos adecuados para ello.

Efectivamente, el TEDH viene señalando de forma habitual que los Estados no pueden sustituir su juicio frente al del propio tribunal en relación con la conveniencia de adoptar una determinada medida cautelar. Si un Estado tienen información relevante en relación con la necesidad de levantar una determinada medida cautelar, deberá informar al TEDH para que adopte la decisión que considere conveniente ${ }^{38}$. Entre tanto, el Estado tiene obligación de cumplir la medida cautelar indicada y el TEDH tiene competencia para determinar si el Estado ha cumplido con su obligación, teniendo en cuenta tanto el alcance como la celeridad de las medidas adoptadas, y no si se ha materializado el riesgo que la medida trataba de evitar, tal y como ya se destacó anteriormente ${ }^{39}$. Esta afirmación de competencia no hace sino aquilatar el carácter vinculante de las medidas cautelares dictadas por el TEDH: si éstas son obligatorias para los Estados, vulnerándose el art. 34 $\mathrm{CEDH}$ en caso de incumplimiento, parece evidente que ha de ser el propio TEDH el que determine si éste se ha producido. En relación con los criterios utilizados por el TEDH para determinar tal cuestión, resaltan de forma clara su interpretación extensiva y flexible de los contenidos de las medidas, así como su interpretación exigente del tiempo del que disponen los Estados para cumplirlas.

En lo que a la interpretación del contenido de la medida cautelar se refiere, el TEDH ha subrayado de forma reiterada que no puede hacerse de un modo formalista, ateniéndose únicamente a su formulación literal. Por el contrario, es necesario tener en cuenta el objetivo o el espíritu de la medida a la hora de determinar la existencia de un eventual incumplimiento por parte del Estado demandado ${ }^{40}$. Lo relevante no será tanto que el Estado cumpla con el texto de la medida, sino que ésta tenga un efecto real, alcanzando el objetivo que se proponía.

38 El incumplimiento de la medida, unido a la falta de comunicación del Estado sobre los motivos que justificarían el eventual levantamiento de la misma, parece agravar la responsabilidad estatal, a la luz de las consideraciones que realiza el TEDH en una larga serie de casos contra Italia: SSTEDH Toumi c. Italia, de 5 de abril de 2011; Mannai c. Italia, de 27 de marzo de 2012; Trabelsi c. Italia, de 13 de abril de 2010; Ben Khemais c. Italia, de 24 de febrero de 2009. En el mismo sentido, ver: STEDH Paladi c. Moldavia, Gran Sala, de 10 de marzo de 2009, § 104 39 Ver el apartado anterior y, también, STEDH Paladi c. Moldavia, Gran Sala, de 10 de marzo de 2009, § 90.

40 Ver, STEDH Paladi c. Moldavia, Gran Sala, de 10 de marzo de 2009, § 91; STEDH Klimov c. Rusia, de 4 de octubre de 2016, § 47. 
En este sentido, llaman la atención varios casos en los que el TEDH indicaba a los Estados demandados que no procedieran a extraditar a los demandantes hasta tanto el tribunal no se pronunciara sobre el fondo del asunto por existir un riesgo plausible de violación del art. $3 \mathrm{CEDH}$. Aún con tal advertencia, los demandantes fueron puestos en manos de las autoridades del país que había solicitado la extradición por procedimientos distintos a la extradición o sin seguir ningún tipo de procedimiento legal. En estos asuntos, parecía evidente que el Estado había realizado una interpretación literal de la medida cautelar dictada: no se había extraditado a los demandantes ${ }^{41}$. Aún así, el TEDH entendió violado el art. $34 \mathrm{CEDH}$ ya que se había subvertido la finalidad última de la medida cautelar poniendo a los demandantes en manos de terceros Estados que podían vulnerar el art. 3 CEDH. El TEDH realizaba así una interpretación extensiva del contenido de sus medidas cautelares: lo importante no era tanto que no se hubiera procedido a la extradición, como que no se había alcanzado el objetivo último de la misma, véase, salvaguardar la integridad de los demandantes hasta que hubiera un pronunciamiento sobre el fondo de la demanda formulada.

Igualmente, el TEDH viene subrayando de forma reiterada que los Estados deben cumplir con rigor las medidas cautelares indicadas, cuestión que puede resultar compleja cuando la medida impone obligaciones positivas al Estado. Así, por ejemplo, en el asunto Amirov c. Rusia, de 27 de noviembre de 2014, el TEDH indicó al Estado demandado una medida cautelar doble: el traslado del demandante, privado de libertad y gravemente enfermo, a una institución especializada para su tratamiento; y la creación de una comisión médica independiente de instituciones penitenciarias, que determinara si el tratamiento que el demandante recibía era el adecuado, si su estado de salud era compatible con la permanencia en prisión y si era necesario su traslado a un hospital. El demandante fue atendido por esa comisión médica que, sin embargo, no respondió a las cuestiones plateadas, limitándose a analizar si la enfermedad que sufría podía encuadrarse en las que, según la normativa rusa, determinaban la obligación de poner en libertad a un detenido. El gobierno fue quien contestó a las preguntas del TEDH.

El TEDH consideró vulnerado el art. $34 \mathrm{CEDH}$, argumentando que las autoridades estatales sustituyeron la valoración que debía realizar la comisión experta por su propia valoración, lo que impidió al tribunal obtener mayor información sobre la situación médica del detenido y las condiciones de los establecimientos médicos de la prisión. Se truncaba así uno de los fines de la medida, que no sólo pretendía salvaguardar el estado de salud del demandante, sino también determinar los hechos en los que se basaba la demanda ${ }^{42}$. Y se reflejaba, negro sobre blanco, la interpretación estricta del cumplimiento de las medidas cautelares que realiza el TEDH: las medidas deben cumplirse íntegramente, de modo que un cumplimiento parcial es siempre considerado una violación del art. $34 \mathrm{CEDH}^{43}$.

41 Ver, STEDH Zokhidov c. Rusia, de 5 de febrero de 2013, § 207-208; Savriddin Dzhurayev c. Rusia, de 25 de abril de 2013, § 215-216. Ver también STEDH Abdulkhakov c. Rusia, de 2 de octubre de 2012, en que las autoridades rusas pusieron al demandante a disposición de las autoridades tayikas, y no de las uzbekas, que habían solicitado su extradición, a pesar de la medida cautelar dictada por el TEDH.

42 En una línea semejante, ver: SSTEDH Andrey Lavrov, de 1 de marzo de 2016; Klimov c. Rusia, de 4 de octubre de 2016; Maylenskiy c. Rusia, de 4 de octubre de 2016; Aleksanyan c. Rusia, de 22 de diciembre de 2008

43 En el mismo sentido, ver casos en los que se inicia el tratamiento de un demandante tras la indicación de una medida cautelar por el TEDH, pero no se continua: STEDH Pivovarnik c. Ucrania, de 6 de octubre de 2016. 
Finalmente, llama también la atención la celeridad con la que los Estados deben actuar una vez recibida la indicación de una medida cautelar por parte del TEDH. El TEDH ha subrayado en varias ocasiones que las medidas cautelares deben ser cumplidas de forma urgente ${ }^{44}$, exigiendo su cumplimiento en plazos extraordinariamente breves. El retraso en la adopción de la medida se califica como un incumplimiento. De este modo, no es infrecuente encontrar supuestos en los que el tribunal considera incumplida una medida cautelar y vulnerado el art. $34 \mathrm{CEDH}$ por un retraso que puede ser de apenas unos días ${ }^{45}$.

No obstante, hay que señalar que no queda claro cual es el estándar de celeridad que aplica el TEDH en relación con el cumplimiento de sus medidas. Lo que sí parece evidente es que, en la determinación de la existencia de un eventual incumplimiento, dos elementos serán tenidos en cuenta: la propia dicción de la medida cautelar, en tanto que si se utilizan expresiones que se asocian a la inmediatez en la toma de decisiones, los Estados carecerán de margen alguno de actuación ${ }^{46}$; y, la propia actividad desarrollada por las autoridades estatales, en tanto que si el TEDH observa que no permanecieron pasivas, sino que trataron de dar cumplimiento a la medida, el transcurso de ciertos días entre la adopción de la misma y su cumplimiento puede analizarse de forma más benévola ${ }^{47}$.

Esa diligencia, además, no se ciñe al cumplimiento de la medida cautelar, sino incluso a la propia organización interna del Estado, en la medida en que, en varias ocasiones, el TEDH ha analizado en qué momento se comunica la adopción de la medida al Estado demandado y el procedimiento interno seguido para que esa medida llegue a quien debe ejecutarla efectivamente en el menor tiempo posible. Así, por ejemplo, en el caso Paladi c. Moldavia, Gran Sala, de 10 de marzo de 2009, el TEDH reprochaba al Estado que hubiera tardado cuatro días en ejecutar una medida cautelar y que tratara de justificar tal retraso aduciendo — entre otros motivos - que su agente había recibido la comunicación al día siguiente de su envío por el TEDH.

En su sentencia, el TEDH subrayaba que la comunicación oficial de la medida fue remitida en varias ocasiones al agente del Estado, a quien además se intentó localizar infructuosamente por teléfono en varias ocasiones. El TEDH subrayaba que tales intentos se efectuaron en un día laborable y que, por tanto, no podía justificarse la negligencia del Estado ${ }^{48}$. Llamaba así poderosamente la atención la exigente valoración realizada por el TEDH: los Estados no sólo deben cumplir de forma diligente las medidas cautelares indicadas, sino que deben organizarse internamente para la recepción de las mismas en el

44 Ver, entre otras, STEDH Grori c. Albania, de 7 de julio de 2009, § 190.

45 Entre otras, ver: STEDH Aleksanyan c. Rusia, de 22 de diciembre de 2008 (2 meses); Paladi c. Moldavia, Gran Sala, de 10 de marzo de 2009 (4 días); D.B. c. Turquía, de 13 de julio de 2010 (18 días).

46 En este sentido, ver: STEDH Salakhov y Islyamova c. Ucraniana, de 14 de marzo de 2013, en el que el TEDH subrayaba que el cumplimiento de una medida cautelar tres días después de su adopción vulneró el art. 34 $\mathrm{CEDH}$, en tanto el TEDH exigió el traslado inmediato del demandante a un hospital y la inmediatez se asociaba al cumplimiento en el mismo día en que se dictó la medida cautelar.

47 En este sentido, ver: STEDH Konovalchuk c. Ucrania, de 13 de octubre de 2016, en el que el TEDH validaba el transcurso de 13 días desde que se acordó la medida cautelar y un medico especialista vio al demandante. El TEDH tenía en cuenta que las autoridades no permanecieron pasivas, tratando de conseguir la correspondiente cita médica.

48 Ver, STEDH Mostafa y otros c. Turquía, de 15 de enero de 2008, en el que el TEDH señalaba ya que las autoridades turcas habían tardado 5 días en recibir efectivamente la comunicación oficial de la medida cautelar porque eran festivos. Sobre otros casos semejantes, ver: Burbano Herrera, C. (2012)., op. cit. pp. 52 y ss. 
momento en el que se produce un pronunciamiento del tribunal. Por tanto, la adecuada organización interna forma parte del deber de diligencia que se impone.

\subsection{La exención de la obligación de cumplir las medidas cautelares cuando concurran circunstancias objetivas: un estándar difícil de alcanzar}

Aunque el TEDH ha dejado claro que los Estados no pueden libremente decidir sobre el cumplimiento de sus medidas cautelares, sustituyendo su propio criterio al del tribunal, a partir del caso Paladi c. Moldavia, Gran Sala, de 10 de marzo de 2009, la jurisprudencia europea reconoce formalmente la posibilidad de que los Estados no cumplan con las medidas cautelares cuando prueben que alguna circunstancia objetiva les impidió hacerlo, a pesar de que siguieron todos los pasos razonables para levantar tal impedimento y mantener al TEDH informado al respecto ${ }^{49}$. Siguiendo esta jurisprudencia, podría eximirse a los Estados de la obligación de cumplir una medida cautelar siempre que se dieran ciertas condiciones. Sin embargo, tales exigencias han sido interpretadas de forma tan estricta por el TEDH que, hasta la fecha, la jurisprudencia Paladi no ha sido nunca aplicada con resultados favorables para el Estado incumplidor.

En el ya analizado caso Paladi, primero de los pocos asuntos en los que se ha aplicado esta jurisprudencia, el TEDH entendió que no concurrían las circunstancias objetivas exigidas, en la medida en que el gobierno moldavo intentó justificar su cumplimiento tardío subrayando que el mismo no había tenido ninguna consecuencia y que el retraso se había debido a que su agente recibió la comunicación oficial de la medida cautelar al día siguiente de su envío por el TEDH. Tal y como ya se ha analizado, el TEDH aclaraba de forma tajante que la inadecuada organización interna del Estado no podía considerarse una circunstancias objetiva que justificara el cumplimiento tardío de la medida cautelar.

En posteriores asuntos, el TEDH ha identificado otros motivos que no pueden considerarse circunstancias objetivas que eximen a los Estados del cumplimiento de las medidas cautelares, véase, el deber de dar cumplimiento a otras obligaciones internacionales o a obligaciones derivadas de la legislación interna o circunstancias materiales creadas por la actuación de las propias autoridades estatales.

En relación con la alegación de otras obligaciones internacionales como causa que justificaría el incumplimiento de medidas cautelares por el Estado destaca, sin lugar a dudas, el caso Al-Saadoon y Mufdhi c. Reino Unido, de 2 de marzo de 2010. En ese asunto, el TEDH había adoptado une medida cautelar dirigida a impedir la transferencia de la custodia de los demandantes a las autoridades iraquíes, que podían imponerles la condena a muerte por hechos cometidos durante la guerra de Irak. Las autoridades británicas incumplieron la medida tratando de justificar su actuación aduciendo las obligaciones internacionales que habrían asumido con el Estado iraquí. El TEDH desestimó las

49 El texto original en inglés versa: «It is for the respondent Government to demonstrate to the Court that the interim measure was complied with or, in an exceptional case, that there was an objective impediment which prevented compliance and that the Government took all reasonable steps to remove the impediment and to keep the Court informed about the situation.» (\$ 92). Además de los asuntos que se citarán en el cuerpo del texto, se aplica esta jurisprudencia en: STEDH D.B. c. Turquía, de 13 de julio de 2010. 
alegaciones formuladas señalando que los Estados parte del CEDH no deben asumir obligaciones internacionales contrarias a las derivadas del CEDH y rechazando, por tanto, que un compromiso internacional pudiera considerarse causa objetiva que justificara la falta de cumplimiento de una medida cautelar.

En una línea semejante, en el caso Trabelsi c. Bélgica, de 4 de septiembre de 2014, el TEDH desechaba que las obligaciones internacionales asumidas por el Estado o la aplicación de la normativa interna, que determinaba la puesta en libertad del demandante y el consiguiente riesgo de fuga, pudieran ser motivos objetivos que justificaran el incumplimiento de una medida cautelar, máxime si el Estado no había siquiera tratado de buscar alternativas a la puesta en libertad ${ }^{50}$.

Tampoco circunstancias materiales creadas por el propio Estado y que imposibilitan el cumplimiento de una medida cautelar han sido consideradas por el TEDH como eximentes de la obligación que se deriva del art. $34 \mathrm{CEDH}^{51}$. En ese sentido, dos casos muy recientes ponen en tela de juicio el procedimiento llevado a cabo por las autoridades francesas con miras a expulsar a dos demandantes de asilo hacia Argelia y Marruecos. En los casos M.A y A.S. c. Francia, de 1 de febrero de 2018 y 19 de abril de 2018, el TEDH rechazaba las alegaciones del Estado francés que señalaba la imposibilidad de cumplir la medida cautelar adoptada por el TEDH a fin de evitar la expulsión de ambos demandantes porque cuando ésta fue notificada los dos se encontraban ya dentro del avión que les llevaría a su destino. El TEDH resaltaba que, en ambos casos, la decisión de expulsar había sido adoptada mucho antes de su notificación a los demandantes — un mes antes, en uno de los casos - y que esa notificación se produjo apenas unas horas antes de que ambos fueran embarcados con destino a sus países de origen.

El TEDH señalaba que, con ese proceder, Francia había hurtado a los demandantes la posibilidad de recurrir ante el TEDH, solicitando una medida cautelar que el Estado estuviera en condiciones - temporales - de cumplir, lo que había vulnerado el art. 34 CEDH. El TEDH demostraba así su clara intención de analizar de forma muy rigurosa cualquier alegación dirigida a eximir al Estado de su obligación de dar cumplimiento a las medidas cautelares. Si bien parece evidente que la comunicación de la medida apenas 20 minutos antes de que despegue un vuelo habría sido considerada, con carácter general, una circunstancia objetiva que eximiría de responsabilidad al Estado, el TEDH no se limitaba a esa valoración formal, y con miras a garantizar derechos reales y efectivos, analizaba todas las circunstancias del caso, subrayando de forma clara que fue la negligencia de las autoridades francesas a la hora de notificar las decisiones de expulsión la que impidió la adopción de la medida cautelar en un momento anterior y, por tanto, su consiguiente cumplimiento.

50 En idéntico sentido: STEDH Rrapo c. Albania, de 25 de septiembre de 2012

51 Además de los casos indicados en el cuerpo del texto, se pone en tela de juicio la organización del estado, en este caso en el ámbito sanitario, en Makharadze y Sikharulidze c. Georgia, de 22 de noviembre de 2011. En el citado asunto, el TEDH había adoptado una medida cautelar por la que se imponía el traslado del demandante, gravemente enfermo de tuberculosis, a un hospital especializado. El Estado intentó justificar su incumplimiento alegando que los dos hospitales especializados existentes estaban desbordados y, por tanto, no le habrían podido atender en caso de haberse efectuado el traslado. El TEDH recalcó que la única circunstancia objetiva que habría eximido al Estado de la obligación de cumplir con su medida cautelar habría sido la ausencia total de un hospital de esas características en Georgia. Sin embargo, dado que había dos instalaciones que cumplían los requisitos, el demandante debería haber sido trasladado a una de ellas para ser atendido, teniendo en cuenta la gravedad de su estado y que la atención a pacientes se realiza siempre siguiendo un orden de prioridad establecido en función de criterios médicos. 
A partir de esta jurisprudencia, podemos inferir que el TEDH no considera circunstancias objetivas que eximan a los Estados de la obligación de dar cumplimiento a las medidas cautelares a aquellas que, de un modo u otro, dependen del actuar de las propias autoridades estatales, bien porque asumen obligaciones normativas contrarias al CEDH, bien porque crean situaciones que les impiden de facto dar cumplimiento a tales medidas. Sin embargo, y tal y como ahora veremos, la jurisprudencia del TEDH sí parece identificar como circunstancias objetivas eximentes de la obligación que se impone a los Estados aquellas que son independientes del actuar de las autoridades estatales, como serían por ejemplo, las ligadas al comportamiento del demandante, o a su estado físico.

En este sentido, en el caso Grori c. Albania, de 7 de julio de 2009, el TEDH había ordenado a las autoridades albanesas que el demandante, gravemente enfermo, fuera trasladado a un hospital civil para que se realizara un diagnostico de su situación y se determinara el tratamiento a seguir, pero el demandante se negó al traslado, iniciando una huelga de hambre que retrasó el cumplimiento de la medida cautelar. El demandante fue trasladado y la medida se cumplió, pero 18 días después de su adopción. El TEDH subrayaba que la actuación de las autoridades estatales no era el único elemento a tener en cuenta a la hora de valorar si se había dado cumplimiento a la medida cautelar, siendo también relevantes el comportamiento del demandante y su estado físico. A pesar de ello, el TEDH señalaba que la huelga de hambre del demandante sólo retrasó en 3 días el cumplimiento de la medida, siendo el resto imputable al Estado, que habría incumplido así las obligaciones que se derivan del art. $34 \mathrm{CEDH}$.

Aunque el resultado no era positivo para el Estado, el TEDH reconocía implícitamente que el comportamiento del demandante u otras circunstancias objetivas, como su salud, podrían ser considerados elementos que justificaran un eventual incumplimiento de una medida cautelar. Junto a ellas, otras circunstancias ajenas al comportamiento de las autoridades estatales podrían quizás ser consideradas eximentes de la responsabilidad del Estado, aunque en tales casos y siguiendo el iter del razonamiento del TEDH en Paladi y Grori, las autoridades estatales deberán todavía demostrar que ese impedimento fue la causa del incumplimiento, que trataron de evitarlo adoptando medidas adecuadas y que informaron de las mismas al TEDH. Sin duda, una interpretación más que exigente, que muestra la preocupación del TEDH por asegurar el cumplimiento de sus medidas cautelares, en el evidente entendimiento de que la eficacia de la tarea que desempeña depende, en buena parte, de que los Estados no priven de sentido al derecho a recurrir ante Estrasburgo por la sibilina vía de crear situaciones que sean de facto irreversibles.

\section{ALGUNAS CUESTIONES PROCEDIMENTALES: UN ANÁLISIS ESPECIALMENTE DILIGENTE DEL RIESGO}

Más allá de asegurar el cumplimiento estricto de las medidas cautelares, otro elemento esencial que permite valorar la eficacia de la tutela cautelar garantizada por el TEDH es de tipo procedimental y tiene que ver, fundamentalmente, con la existencia de un procedimiento especialmente ágil que permita al Tribunal pronunciarse sobre estas solicitudes antes de que se haya materializado el riesgo que se pretende evitar. En las medidas cautelares, la agilidad del procedimiento es esencial, en cuanto en ellas se hace especialmente evidente la célebre sentencia de Séneca sobre la injusticia de la justicia tardía. 
En lo que a la agilidad del procedimiento previsto para solicitar y pronunciarse sobre las medidas cautelares se refiere, el TEDH parece constituir un claro ejemplo a seguir, especialmente tras las novedades en el tratamiento de estas solicitudes que se introdujeron en el año 2011 como respuesta al fuerte incremento de las solicitudes del año $2010^{52}$. El art. 39 del Reglamento interno del TEDH aporta escasa luz sobre el procedimiento a seguir para solicitar y tramitar las solicitudes de medidas cautelares, al limitarse a prever que el TEDH puede concederlas de oficio, o a petición de una parte u otro interesado, y quien está facultado para adoptarlas, esto es, fundamentalmente las Salas, los Presidentes de Sección u otros jueces a los que se asigne tal función ${ }^{53}$.

Nada nos dicen esos elementos sobre la agilidad del procedimiento. Sin embargo, la Guía práctica sobre medidas cautelares aprobada por el Presidente del TEDH aporta mayor luz al respecto ${ }^{54}$. Se desprende de ella, que el solicitante no tiene necesariamente que cumplir las rigurosas instrucciones para la presentación habitual de una demanda ante el TEDH ${ }^{55}$. Se pide así que la solicitud de medidas cautelares se haga por escrito, por correo postal o vía fax, pero no que se adjunte necesariamente el modelo de demanda que exige Estrasburgo ${ }^{56}$. En lógica con esta flexibilización del procedimiento ordinario, el TEDH puede pronunciarse sobre las medidas cautelares antes de la recepción del escrito de demanda y sin necesidad de adoptar una concreta decisión sobre la admisibilidad de la misma ${ }^{57}$. A pesar de ello, la práctica del TEDH implica cada vez más la adopción conjunta de una decisión de inadmisión si se desestima la solicitud de la medida cautelar, o de una decisión de comunicar el caso al Estado y darle prioridad si la decisión respecto de la medida cautelar es estimatoria, práctica que ha mejorado notablemente el procedimiento ante el tribunal y reducido los plazos de resolución de aquellos asuntos sobre los que pende una medida cautelar ${ }^{58}$.

En línea con la idea de agilizar el procedimiento ordinario y adecuarlo a las exigencias de la tutela cautelar, la Guía práctica sugiere también que la solicitud de medidas cautelares se efectúe tan pronto como sea posible — sin esperar, por tanto, al período de seis meses habitualmente fijado para la presentación de una demanda-, y consignando claramente el día y la hora en que la persona será expulsada o extraditada, si ese es el objeto del litigio. Incluso, se sugiere que la solicitud se formule antes de que se haya adoptado la decisión nacional definitiva si ésta se prevé inminente y existe un riesgo de ejecución inmediata ${ }^{59}$. El objetivo, en este caso, parece claro: el TEDH ha de tener tiempo

52 Sobre los mismos, ver Council of Europe, Steering Committee for Human Rights, Report on interim measures under Rule 39 of the Rules of Court, de 22 de marzo de 2013, par. 11 y ss.

53 Sobre ambas cuestiones, ver: Keller, H. y Marti, C., op. cit., p. 329 y ss.

54 Practice Directions, Request for interim measures, adoptadas el 5 de marzo de 2003 y reformadas en última ocasión el 7 de julio de 2011 (accesible en https://www.echr.coe.int/Documents/PD_interim_measures_ ENG.pdf).

55 Sobre la materia, más allá de lo contenido en el texto del CEDH y lo Estattutos del TEDH, es recomendable leer la guía práctica para la presentación de demandas: Practice Directions, Institution of proceedings, adoptadas por el Presidente del TEDH el 1 de noviembre de 2003 y modificadas por última vez el 5 de octubre de 2015.

56 Ver, Practice Directions, Request for interim measures, cit. supra, aptdo. II.

57 Ver, como ejemplo práctico, la STEDH Trabelsi c. Bélgica, de 4 de septiembre de 2014, par. 147, en la que el Estado demandando criticaba que el TEDH no hubiera realizado un análisis de admisibilidad antes de adoptar la medida cautelar.

58 Sobre esta práctica y sus aspectos positivos, ver: Council of Europe, Steering Committee for Human Rights, Report on interim measures under Rule 39 of the Rules of Court, de 22 de marzo de 2013, par. 13 y ss.

59 Ver, Practice Directions, Request for interim measures, cit. supra, aptdo. III. 
para analizar la solicitud y todas estas indicaciones tratan de evitar que, en ese lapso de tiempo, la decisión nacional se ejecute y la medida cautelar pierda su sentido.

De hecho, el TEDH asume una pesada carga al respecto, ya que debe responder a estas solicitudes, en muchas ocasiones, en tiempos extraordinariamente breves, como se deduce del hecho de que la propia Guía práctica señale que puede no ser capaz de responder una solicitud presentada con menos de un día laborable ${ }^{60}$. Su jurisprudencia demuestra, a pesar de tal indicación, que el procedimiento puesto en marcha por el TEDH en 2011 , centralizando el análisis de las medidas cautelares en una unidad especializada ${ }^{61}$, le permite analizar y responder las solicitudes de medidas cautelares en apenas unos días ${ }^{62}$ $y$, en algún caso, incluso en el mismo día en que son presentadas ${ }^{63}$.

Finalmente, un último elemento que da idea de la agilidad que pretende imprimirse al procedimiento aparece también reflejado en la Guía práctica, en la que se señala que habrán de agotarse todos los recursos nacionales que tengan carácter suspensivo ${ }^{64}$. Ese requerimiento debe leerse a sensu contrario, en la medida en que la exigencia excluye a aquellos recursos que no tengan carácter suspensivo, de modo que se admite de forma evidente que el TEDH se pronuncie sobre una medida cautelar cuando el demandante cuente todavía con recursos nacionales que agotar, siempre que éstos no tengan carácter suspensivo. Se flexibiliza así uno de los criterios capitales de admisión de demandas ante Estrasburgo, véase, el agotamiento de los recursos internos, con el objetivo claro de garantizar de forma efectiva los derechos de los demandantes. De nada serviría este procedimiento si los Estados pudieran evitar la adopción de medidas cautelares eficaces por la simple vía de crear o mantener recursos internos que dilataran el proceso sin suspender la ejecución de la medida.

Analizados estos concretos elementos, parece claro que el TEDH ha sido capaz de adecuar su procedimiento ordinario a las exigencias de inmediatez y agilidad que imponen las medidas cautelares. Aún así, un último elemento parece esencial para valorar la capacidad del TEDH de hacer frente a los retos que plantea la tutela cautelar, en concreto, los requisitos que han de cumplirse para la adopción de una medida de este tipo.

\section{LOS CRITERIOS A CONSIDERAR EN EL JUICIO CAUTELAR: RIESGO REAL E INMINENTE Y DAÑO GRAVE E IRREPARABLE}

El artículo 39 del Reglamento del TEDH ayuda poco en la tarea de delimitar los elementos que han de concurrir para que el tribunal adopte una medida cautelar, al prever únicamente que se adoptarán las que se consideren apropiadas en interés de las partes y del correcto desarrollo del proceso. Por tanto, ha sido el TEDH, a través de su

60 Idem supra.

61 Sobre este procedimiento, ver: Keller, H. - MARTI, C., op. cit., p. 335 y ss.; Council of Europe, Steering Committee for Human Rights, Report on interim measures under Rule 39 of the Rules of Court, de 22 de marzo de 2013, par. 11.

62 Por ejemplo, en STEDH Maylenskiy c. Rusia, de 4 de octubre de 2016, el TEDH tardaba 11 días en responder a la solicitud de medidas cautelares; en Amirov c. Rusia, de 27 de noviembre de 2014, tardaba 3 días; en Grori c. Albania, de 7 de julio de 2009, tardaba 7 días.

63 Ver, STEDH Trabelsi c. Bélgica, de 4 de septiembre de 2014.

64 Ver, Practice Directions, Request for interim measures, cit. supra, aptdo. IV. 
jurisprudencia, el que ha definido los criterios relevantes, aparentemente inspirados en la experiencia de otros tribunales internacionales ${ }^{65}$. Según su jurisprudencia, las medidas cautelares sólo se adoptan en casos excepcionales ${ }^{66}$, cuando el demandante alega de forma plausible la existencia de un riesgo inminente de que se produzca un daño grave e irreparable en el disfrute de uno de los derechos que conforman el núcleo duro del $\mathrm{CEDH}^{67}$.

Teniendo en cuenta esa jurisprudencia, parece evidente que hay varios elementos clave que permiten determinar si procede la adopción de la medida cautelar por parte del TEDH, en concreto, la noción de riesgo plausible e inminente y de daño grave e irreparable. La determinación de la interpretación que debemos hacer de cada uno de estos elementos resulta compleja dado que las decisiones en la materia están claramente vinculadas a los hechos del caso, haciendo difícil la construcción de una teoría general. A este elemento, se añade el hecho de que las decisiones por las que el TEDH adopta medidas cautelares no se hacen públicas, notificándose únicamente a las partes afectadas, a las que además no suele explicarse el motivo por el que se ha estimado o desestimado su petición ${ }^{68}$. De este modo, sólo podemos utilizar como instrumento de análisis los escasos datos que se recogen en aquellas sentencias o decisiones del TEDH en que se menciona que el tribunal adoptó una medida cautelar en el caso concreto. Ante tan escasa fuente de información, la prudencia se impone.

\section{El daño grave: ¿una noción limitada a la eventual vulneración de derechos concretos?}

La gravedad del daño, esencial para determinar los supuestos en los que el TEDH concederá una medida cautelar no aparece concretada en la jurisprudencia del tribunal, aunque en algunos asuntos, parece claramente vinculada al derecho fundamental alegado por el demandante y a la pertenencia del mismo a lo que el tribunal considera el núcleo duro de los derechos convencionales. De hecho, la jurisprudencia del TEDH explicita la gravedad del daño que exige a través de dos frases recurrentes que nos dan una idea de los limitados casos en los que el TEDH concederá una medida cautelar ${ }^{69}$.

En algunos asuntos, el TEDH señala que la mayoría de sus medidas cautelares se adoptan cuando el demandante hace frente a una amenaza seria para su vida o integridad física $^{70}$. En otros, el TEDH hace referencia directamente a los derechos que constituirían el núcleo duro del $\mathrm{CEDH}$, identificándolos con el derecho a la vida (art. 2 CEDH), el

65 Sobre las exigencias de urgencia, irreparabilidad del daño, y existencia prima facie de un caso a favor del demandante en la jurisprudencia de otros tribunales internacionales, ver: Cameron, A.M., op. cit., p. 192 y ss. y 224 y ss.

$66 \mathrm{La}$ excepcionalidad de las circunstancias en que se adoptan ha sido subrayada, por ejemplo, en STEDH Klimov c. Rusia, de 4 de octubre de 2016, § 43.

67 Entre muchas otras, ver: STEDH Savriddin Dzhurayev c. Rusia, de 25 de abril de 2013, § 213 o Klimov c. Rusia, de 4 de octubre de 2016, $\S 43$ : «The crucial significance of interim measures is further highlighted by the fact that the Court issues them, as a matter of principle, in truly exceptional cases on the basis of a rigorous examination of all the relevant circumstances. In most of these, the applicants face a genuine threat to life and limb, with the ensuing real risk of grave, irreversible harm in breach of the core provisions of the Convention».

68 Algunos autores han criticado esta falta de transparencia, ver: Keller, H. y Marti, C., op. cit., p. 338.

69 Esa referencia a la limitación de los supuestos en que el TEDH adopta medidas cautelares es recurrente en la jurisprudencia. Entre otras, ver STEDH Mamatkulov y Askarov c. Turquía, Gran Sala, de 4 de febrero de 2005, § 104

70 Entre otros, ver STEDH Savriddin Dzhurayev c. Rusia, de 25 de abril de 2013, § 213 
derecho a no sufrir malos tratos (art. $3 \mathrm{CEDH}$ ) y, en casos excepcionales, el derecho a la vida privada y familiar (art. $8 \mathrm{CEDH}$ ) y otros derechos del Convenio ${ }^{71}$. En ambos supuestos, la conclusión es idéntica, asociándose el daño protegible a través de una medida cautelar esencialmente con aquel que constituiría una amenaza seria para la vida o la integridad física del demandante.

No es de extrañar así que la mayoría de las medidas cautelares se refieran a supuestos en los que esos derechos están en liza y la amenaza es particularmente seria ${ }^{72}$. En relación con el derecho a la vida, se han concedido medidas cautelares cuando el demandante podía verse imponer la pena de muerte en caso de ser extraditado a otro país ${ }^{73}$, podía correr idéntica suerte a manos de las autoridades de su país u otros agentes en caso de ser expulsado ${ }^{74}$, o incluso cuando su vida dependía de la decisión de iniciar o continuar un determinado tratamiento médico ${ }^{75}$. En todos estos casos, el riesgo grave se identifica con la pérdida de la vida humana, de modo que la medida cautelar es levantada por el TEDH cuando ya no existe tal riesgo, por ejemplo, porque las autoridades del país al que va a ser extraditado el demandante se han comprometido a respetar tal derecho ${ }^{76}$.

En relación con la prohibición de malos tratos contenida en el art. $3 \mathrm{CEDH}$, la mayoría de las medidas cautelares adoptadas se refieren también a casos de extradición o expulsión ${ }^{77}$, en los que el demandante aduce la existencia de un riesgo real de sufrir tratos contrarios al CEDH en el país de destino ${ }^{78}$, como podrían ser la condena a prisión permanente no revisable ${ }^{79}$, a ser lapidada por adulterio ${ }^{80}$, la posibilidad de ser objeto de mutilación genital ${ }^{81}$, de explotación sexual ${ }^{82} \mathrm{o}$, incluso, de una suerte de ostracismo social que impediría al afectado desarrollar una vida normal y cubrir sus necesidades más básicas $^{83}$.

71 Entre otros, ver STEDH Al-Saadoon y Mufdhi c. Reino Unido, 2 de marzo de 2010, § 160

72 Para un análisis detallado del contenido y los supuestos en que el TEDH ha adoptado medidas cautelares, ver: Whatthée, S., p.. 167 y ss.; Keller, H., Marti, C., op. cit., p. 346 y ss.; Morte Gómez, C., Cómo presentar una demanda ante el Tribunal Europeo de Derechos Humanos. Modificaciones tras la entrada en vigor del Protocolo $n .^{\circ} 14$. Tirant lo Blanch: Valencia, 2011, p.. 213 y ss.

73 Ver, TEDH, Nivette c. Francia, Decisión de admisibilidad de 3 de julio de 2001.

74 Ver, STEDH F.G. c. Suecia, Gran Sala, de 23 de marzo de 2016, en la que el TEDH indicaba a las autoridades suecas que no expulsarán a la demandante hacia Irán por existir un riesgo real de vulneración de los derechos reconocidos en los arts. 2 y 3 CEDH dad su conversión al cristianismo.

75 Ver, STEDH Lambert y otros c. Francia, Gran Sala, de 5 de junio de 2015, en la que el TEDH indicaba a las autoridades francesas que no ejecutaran la decisión del Consejo de Estado de suspender la alimentación e hidratación artificial de un paciente en estado vegetativo.

76 Así ocurrió, por ejemplo, en Nivette c. Francia, Decisión de admisibilidad de 3 de julio de 2001, en que el TEDH levantó la medida cautelar que instaba la no extradición del demandante, cuando las autoridades estadounidenses, que la habían solicitado, se comprometieron a no imponer la condena a muerte o la prisión permanente.

77 Para un análisis detallado de las medidas cautelares adoptadas en casos de extradición y expulsión, ver: European Council of Refugees and Exile, Research on ECHR Rule 39 Interim Measures, 2012; Burbano Herrera, C., y Haeck, Y., «Staying the Return of Aliens from Europe through Interim Measures: The Case-law of the European Commission and the European Court of Human Rights». European Journal of Migration and Law, vol. 13, 2011, p. $31-51$

78 Entre muchos otros, ver: STEDH Toumi c. Italia, de 5 de abril de 2011; Ben Khemais c. Italia, de 24 de febrero de 2009 .

79 Ver, STEDH Babar Ahmad and Others v. the United Kingdom, de 10 de abril de 2012.

80 Ver, STEDH Jabari c. Turquía, de 11 de julio de 2000.

81 Ver, STEDH Sow c. Bélgica, de 19 de enero de 2016.

82 Ver, STEDH M. c. Reino Unido, Decisión de 1 de diciembre de 2009.

83 Ver, STEDH N. c. Suecia, de 20 de julio de 2010. 
En este grupo, destaca también la adopción de medidas cautelares en casos de demandantes gravemente enfermos que, bien van a ser expulsados hacia países en los que podrían verse privados de la medicación de la que dependen ${ }^{84}$, bien están privados de libertad y no se les permite acceder a un tratamiento médico adecuado ${ }^{85}$. En estos casos, el análisis de la gravedad de la enfermedad que afecta al demandante suele ser muy riguroso, encontrándonos ante supuestos de grave deterioro del estado de salud, como se desprende del hecho de que, en algunos casos, se haya producido la muerte poco después de la adopción de la medida cautelar, a pesar de que el TEDH haya indicado la continuación —o inicio- del tratamiento médico apropiado ${ }^{86}$. En esa lógica, parece poder afirmarse que sólo los casos más graves de violación del art. $3 \mathrm{CEDH}$, aquellos en los que la integridad del sujeto se vea seriamente afectada, darán lugar a la indicación de una medida cautelar por parte del TEDH ${ }^{87}$.

Más allá de las medidas cautelares justificadas por la existencia de un riesgo grave de violación de los arts. 2 y $3 \mathrm{CEDH}$, los casos en que el TEDH ha resuelto en positivo una petición de medidas cautelares son escasos, y se vinculan a la existencia de un riesgo relacionado con la prohibición de esclavitud o servidumbre (art. $4 \mathrm{CEDH}$ ), el derecho a la vida privada y familiar (art. $8 \mathrm{CEDH}$ ), el derecho a un proceso justo (art. $6 \mathrm{CEDH}$ ) y el derecho a presentar una demanda individual ante el propio TEDH (art. $34 \mathrm{CEDH}$ ).

En relación con el primero, hay que señalar que el TEDH ha concedido medidas cautelares prohibiendo la expulsión de no nacionales que alegaban haber sido tratadas y temían por su suerte en caso de ser retornadas al país en el que la correspondiente red de tráfico de personas las había captado ${ }^{88}$. El TEDH actuaba en el entendimiento de que la trata de personas es una forma moderna de esclavitud que, conforme a su jurisprudencia, vulnera el art. $4 \mathrm{CEDH}^{89}$.

En relación con el derecho a la vida privada y familiar, parte de los asuntos en los que el TEDH ha adoptado una medida cautelar implicaban la inminente separación de padres e hijos, bien porque los primeros iban a ser expulsados ${ }^{90}$, bien porque los segundos iban a ser devueltos a otro país en virtud de lo previsto en el Convenio sobre los Aspectos Civiles de la Sustracción Internacional de Menores $^{91}$ o iban a ser objeto de una medida de protección que implicaba la separación de sus progenitores ${ }^{92}$.

En otros casos, el TEDH ha adoptado una medida cautelar dirigida a frenar el lanzamiento de los demandantes, mientras trataba de determinar si la pérdida de la vivienda habitual producía una vulneración de los arts. 3 ó $8 \mathrm{CEDH}$. Llamativamente, en estos

84 Ver, STEDH Paposhvili c. Bélgica, Gran Sala, de 13 de diciembre de 2016.

85 Ver, STEDH Kofsaftis c. Grecia, de 12 de junio de 2008. Un caso específico es quizás el de los detenidos que comienzan una huelga de hambre, en la medida en que no podemos hablar de enfermedad, pero el TEDH ha requerido en ocasiones a los Estados demandados que aseguraran condiciones de detención conformes a su estado de salud: STEDH Ilascu y otros c. Moldavia y Rusia, Gran Sala, de 8 de julio de 2004.

86 Entre otros, STEDH Salakhov and Islyamova c. Ucrania, de 14 de marzo de 2013.

87 En este sentido, Whatthée, S., op. cit., p. 210 y ss., que sugiere que no se indican medidas cautelares en aquellos casos en que el maltrato podría calificarse de trato degradante, sino sólo cuando estamos ante malos tratos caracterizables como tortura, afirmación a la que entiendo debe añadirse los tratos inhumanos.

88 Por ejemplo, ver TEDH D.O.R. y S.E. c. España, Decisión de admisibilidad de 29 de septiembre de 2015

89 Por ejemplo, ver STEDH Rantsev c. Chipre y Rusia, de 7 de enero de 2010.

90 Por ejemplo, ver STEDH Amrollahi c. Dinamarca, de 11 de julio de 2002.

91 Por ejemplo, ver STEDH Neulinger y Shuruk, Gran Sala, de 6 de julio de 2010.

92 Por ejemplo, ver STEDH Soares de Melo c. Portugal, de 16 de febrero de 2016. 
casos, la obligación de abandonar sus hogares afectaba a colectivos especialmente vulnerables — niños, personas mayores o con alguna discapacidad-, cuya protección parecía justificar la adopción de la medida cautelar por parte del $\mathrm{TEDH}^{93}$. En estos dos grupos de supuestos, la justificación de la medida cautelar parecía hallarse en la aparente intención del tribunal de proteger el interés superior de los menores afectados o de otros colectivos especialmente vulnerables.

No obstante, un caso atípico es quizás el famoso asunto Evans c. Reino Unido, Gran Sala, de 10 de abril de 2007, en el que el TEDH indicó al Estado que no destruyera los embriones creados por la demandante y su ex pareja, mientras dilucidaba si la normativa nacional que imponía tal obligación en caso de que uno de los donantes retirara su consentimiento para el tratamiento de fertilidad vulneraba el art. $8 \mathrm{CEDH}$. En este caso, el carácter irreparable del daño parecía evidente, aunque no tanto su gravedad, al menos si limitamos ésta, como indica el TEDH, a los supuestos más graves de vulneración de los derechos que constituyen el núcleo duro del CEDH.

Finalmente, el TEDH también ha adoptado algunas medidas cautelares que se vinculan claramente con la existencia de un riesgo grave de violación del art. 6 ó 34 CEDH, véase, por ejemplo, el caso Öcalan c. Turquía, Gran Sala, de 12 de mayo de 2005, en el que el TEDH instó a las autoridades turcas a respetar el derecho a un proceso justo del demandante, incurso en un proceso penal que podía acabar en una condena a muerte (art. $6 \mathrm{CEDH})$, así como su derecho a ser debidamente asistido por un letrado de su elección en el procedimiento ante el TEDH (art. $34 \mathrm{CEDH})^{94}$. En estos casos, la gravedad de la vulneración procedimental parece venir, claramente, del vínculo de la misma con otro derecho sustantivo, véase, el derecho a la vida, que el TEDH considera como parte del núcleo duro de los derechos convencionales ${ }^{95}$.

La gravedad del daño se reconduce pues, en la mayoría de los casos, a un riesgo especialmente grave de violación de ciertos derechos del CEDH, esencialmente, el derecho a la vida y la prohibición de tratos inhumanos, aunque la menos habitual inclusión de otros derechos entre aquellos que justificarían la adopción de medidas cautelares por parte del TEDH genera ciertas dudas sobre la consistencia de la jurisprudencia europea. Al fin y al cabo, el análisis de la gravedad del daño que realiza el TEDH parece basarse en una suerte de jerarquización de los derechos reconocidos en el $\mathrm{CEDH}^{96}$, jerarquización que es difícilmente explicable si se tiene en cuenta que no tiene fundamento en ninguno de los preceptos del CEDH y que plantea numerosas dudas relacionadas no sólo con los derechos que parecen ubicados en la parte superior de la pirámide, sino también con el análisis del tipo de daño que el TEDH parece considerar grave.

Efectivamente, hay que señalar que el art. 15.2 CEDH, que recoge los derechos que no pueden ser objeto de ninguna derogación haciendo referencia al derecho a la vida (art. $2 \mathrm{CEDH}$ ), a la prohibición de malos tratos (art. $3 \mathrm{CEDH}$ ), a la prohibición de esclavitud o servidumbre (art. 4.1 CEDH), y al principio de legalidad penal (art. $7 \mathrm{CEDH}$ ), podría

93 Esta justificación es especialmente evidente en STEDH Yordanova y otros c. Bulgaria, de 24 de abril de 2012, pero puedo observarse también en STEDH Raji y otros c. España, de 16 de diciembre de 2014, o en STEDH A.M.B. y otros c. España, de 28 de enero de 2014.

94 En relación con este último, ver también STEDH X. C. Croacia, de 7 de julio de 2008.

95 En este sentido, Whatthée, S., op. cit., p. 512.

96 En este sentido, Whatthée, S., op. cit., p. 248 y ss. 
ser un instrumento útil para establecer una suerte de jerarquía entre los derechos del Convenio. Sin embargo, el recorrido por los grandes grupos de medidas cautelares que el TEDH ha adoptado permite concluir que el tribunal no ha utilizado ese precepto como justificación de su jerarquización de los derechos establecidos en el CEDH, en la medida en que, salvo error por mi parte, no ha adoptado medida cautelar alguna para salvaguardar el derecho reconocido en el art. $7 \mathrm{CEDH}^{97}$, y, por el contrario, sí ha adoptado medidas cautelares tendentes a proteger derechos no contemplados por el precepto.

Una vez descartada esta posible explicación, la jurisprudencia del TEDH entorno a la gravedad del daño parece tambalearse: nada parece justificar que el TEDH rechace adoptar medidas cautelares vinculadas al ejercicio del derecho a unas elecciones libres o al derecho de asociación, ambos esenciales en cualquier sociedad democrática ${ }^{98}$, mientras acepta adoptar medidas cautelares en el ámbito del derecho a la vida privada y familiar, por indicar tan sólo un ejemplo. Igualmente, resulta difícil explicar que la mayoría de las medidas cautelares del TEDH ligadas a la alegación del art. $3 \mathrm{CEDH}$ tengan como contenido prohibir la expulsión o extradición del demandante, cuando otros posibles motivos de violación de ese mismo derecho parecen tener, cuando menos, una gravedad semejante a la indicada ${ }^{99}$, véase, por ejemplo, los casos de condiciones de detención penosas o, más específicamente, los supuestos en que menores extranjeros son privados de libertad en centros para adultos totalmente inadaptados para ellos ${ }^{100}$. A pesar de ello, el TEDH no parece proclive a adoptar medidas cautelares en ese tipo de $\operatorname{casos}^{101}$, como tampoco en casos de daños medioambientales, que el TEDH ha analizado en ocasiones bajo la óptica del art. $8 \mathrm{CEDH}$ y que ya han sido objeto de tutela cautelar por otros tribunales internacionales ${ }^{102}$.

En esa lógica, no es de extrañar que algunos autores hablen de la necesidad de ampliar el horizonte del daño grave que ha delimitado la jurisprudencia del TEDH, apostando por la adopción de medidas cautelares en relación con cualquier derecho de los reconocidos en el CEDH siempre que se den el resto de las condiciones fijadas por la jurisprudencia europea y estemos ante un daño que todavía no se ha materializado o que continúa en el momento en que el demandante acude a Estrasburgo ${ }^{103}$. Para algunos, esa opción pondría en pie de igualdad a todos los derechos reconocidos en el CEDH y, sobre todo, iría en línea con la jurisprudencia del TEDH que llama a la garantía de derechos reales y efectivos: si el TEDH está en condiciones de evitar o hacer cesar un daño grave a cualquiera de los derechos reconocidos en el CEDH, su obligación es hacerlo, sin ceñirse a una suerte de jerarquización indeterminada de los derechos del Convenio ${ }^{104}$.

97 En este sentido, Whatthée, S., op. cit., p. 249 y ss.

98 Ver la indicación al respecto contenida en TEDH, Factsheet on Interim measures, 2018, accesible en https:// www.echr.coe.int/Documents/FS_Interim_measures_ENG.pdf.

99 Un análisis extensivo de estos supuestos puede verse en: Whatthée, S., op. cit., p. 262.

100 En este sentido, ver STEDH Muskhadzhiyeva y otros c. Bélgica, de 10 de enero de 2010; Rahimi c. Grecia, de 5 de abril de 2011; o Sh. D. y otros c. Grecia, comunicado al Estado el 15 de marzo de 2016 (Demanda n. ${ }^{\circ}$ $14165 / 16)$, en que no consta que se acordara ninguna medida cautelar a pesar de que los demandantes eran menores extranjeros no acompañados.

101 Salvo error por mi parte, se ha adoptado una única medida cautelar en ese sentido en el caso Darboe y Camara c. Italia, comunicado al Estado el 18 de enero de 2017 (Demanda n. ${ }^{\circ}$ 5797/17)

102 En este sentido, ver Cameron, A.M., op. cit., p. 228 y ss., sobre medidas cautelares adoptadas por la Corte Internacional de Justicia teniendo en cuenta el daño medioambiental.

103 En esta línea, ver: Whatthée, S., op. cit., p. 273.

104 Idem supra. 


\section{El daño irreparable: ¿una clara conexión con el objeto del proceso?}

En su determinación de los elementos que han de concurrir para la adopción de una medida cautelar en un caso concreto, el TEDH hace alusión de forma reiterada al carácter irreparable del daño que se pretende evitar. Ese concepto no es nuevo en Derecho nacional o internacional, habiéndose interpretado fundamentalmente en dos sentidos distintos, véase, el daño irreparable como aquel imposible de ser compensado o restituido a través, por ejemplo, del pago de una indemnización o cualquier otra fórmula, o el daño irreparable como aquel que convertiría la resolución judicial que ponga fin al proceso en inútil, al ser de imposible cumplimiento por la pérdida de su objeto ${ }^{105}$.

La primera acepción avocaría seguramente al entendimiento de que no procede la adopción de medida cautelar alguna, ya que recordemos que el TEDH, junto con muchos otros tribunales, concede indemnizaciones incluso para las pérdidas más irreparables, véase, las que afectan a la vida humana. Por tanto, parece más sensato tomar como referente la segunda acepción de daño irreparable, esto es, aquella que vincula la irreversibilidad con la finalidad de preservar el objeto del proceso y, por tanto, con el intento de garantizar la posibilidad de restituir al demandante en la integridad de su derecho en caso de que la resolución de fondo sea estimatoria. Así parece haberlo entendido el propio TEDH, al establecer un claro vínculo entre el carácter irreparable del daño y el objetivo de las medidas cautelares de preservar el status quo, el objeto del proceso, a fin de permitir al tribunal analizar de forma efectiva la demanda presentada, asegurar la protección eficaz de los derechos del demandante y garantizar que el fallo definitivo podrá efectivamente cumplirse $\mathrm{c}^{106}$.

En esta lógica, coincido con Whatthée en observar la tendencia del TEDH a entender por daño irreparable sólo aquel que impedirá que su pronunciamiento final se produzca o tenga algún efecto útil ${ }^{107}$. Así, algunas medidas cautelares se justificarán porque su objetivo no es otro que permitir al TEDH analizar de forma efectiva el caso planteado. Este objetivo justifica muchas decisiones del TEDH de prohibir la expulsión de demandantes de protección internacional: el temor es que la víctima desaparezca y deje de tener contacto con sus letrados, lo que impediría la continuación del procedimiento ante el propio $\mathrm{TEDH}^{108}$. Lo mismo ocurre en aquellos casos en los que el TEDH indica medidas positivas que afectan a demandantes privados de libertad, que están gravemente enfermos y no están siendo convenientemente tratados. Más allá de que el TEDH pueda pedir el ingreso del paciente en un establecimiento médico especializado, en varios asuntos se ha indicado al Estado la obligación de constituir una comisión médica que valore al paciente y determine si el establecimiento penitenciario en que se encuentra es adecuado para el tratamiento que necesita. Si no se cumple esta última medida, el TEDH observa que se le ha impedido analizar de forma efectiva los hechos del caso, ya que será imposible determinar aspectos fácticos relacionados con el núcleo mismo de la demanda

105 En este sentido, ver: Cameron, A.M., op. cit., p. 221 y ss.; Castillo de la Torre, F., «Interim measures in community courts: recent trends», Common Market Law Review, n. ${ }^{\circ} 44,2007$, p. $283-284$.

106 Entre otras, ver STEDH Zokhidov c. Rusia, de 5 de febrero de 2013, § 199-200. En este sentido, ver también: Whatthée, S., op. cit., p.222 y ss.

107 En este sentido, Whatthée, S., op. cit., p. 223 yss.

108 WhatThée, S., op. cit., p. 226 y ss. 
presentada $^{109}$. En idéntica línea estarían aquellos casos en los que la medida cautelar indicada tiene por objeto garantizar que el demandante se encuentre debidamente representado ante el propio TEDH.

Si bien en estos supuestos, la medida cautelar busca garantizar el correcto desarrollo del procedimiento ante el TEDH, en otro gran grupo de casos, el objetivo es evitar que la resolución judicial definitiva devenga fútil porque el objeto mismo del proceso desaparezca antes del pronunciamiento del tribunal. Así, en aquellos casos en que el proceso pretende evitar la muerte del demandante, que sea sometido a tortura, que se deteriore grave e irreversiblemente su estado de salud o que caiga en manos de una red de trata de personas, si ese daño se materializa, parece evidente que la resolución judicial definitiva carecerá de eficacia alguna ${ }^{110}$. Lo mismo ocurrirá, por ejemplo, si el demandante es extraditado hacia un tercer país, ajeno al CEDH, y el TEDH determina a posteriori que existe un riesgo real de sufrir malos tratos en el mismo. Aunque el riesgo no se haya materializado, la sentencia de Estrasburgo no podrá ser ejecutada, al encontrarse el demandante en un país no vinculado por las obligaciones derivadas del $\mathrm{CEDH}^{111}$. El objeto del proceso habrá desaparecido irremediablemente y el daño será irreversible, definitivo, imposible de revertir por una decisión ulterior del Estado demandado.

Por contraposición, en aquellos casos en que la violación del derecho es temporal y puede ser revertida por una actuación ulterior del Estado, el TEDH no adoptará normalmente medidas cautelares. Así ocurrirá, por ejemplo, en los casos de expulsiones que afectan a la vida privada y familiar, en tanto el demandante podrá siempre volver al Estado demandado y reconstruir su vida; o en los supuestos de vulneración del art. 5 $\mathrm{CEDH}$, en la medida en que el demandante podrá siempre ser puesto en libertad; o en aquellos en los que se alega la vulneración del art $3 \mathrm{CEDH}$ por condiciones de detención penosas, en la medida en que el demandante podrá siempre ser trasladado a otro centro de detención o puesto en libertad. En el entretanto, es evidente que los demandantes sufren daños graves, pero no irreparables en el sentido estricto en que parece haberlo entendido el TEDH, ya que la vulneración del derecho será, en todo caso, temporal y, por tanto, reversible ${ }^{112}$.

Tal y como señala Whatthée ${ }^{113}$, algunos ejemplos de medidas cautelares acordadas por el TEDH no parecen encajar en esta concepción estrecha del carácter irreparable del daño, véase, aquellos casos en que se ha prohibido el lanzamiento de los inquilinos de una vivienda mientras eran reubicados o, incluso, los recientes asuntos en que el TEDH ha ordenado a un Estado trasladar a menores extranjeros no acompañados a centros apropiados para su condición. En estos casos, parece evidente que la vulneración sería temporal y que el procedimiento podría, en principio, continuarse ante el TEDH, de modo que el tribunal parece haber flexibilizado su criterio habitual, primando la gravedad del daño frente a su carácter irreparable y atendiendo así a la otra gran finalidad de las medidas cautelares: la preservación de los derechos de las partes. No obstante, hablamos de casos aislados, que tan sólo hacen pensar en un posible cambio en la jurisprudencia del TEDH.

109 Entre otras, ver STEDH Aleksanyan c. Rusia, de 22 de diciembre de 2008, § 231.

110 WhatThÉE, S., S., op. cit., p. 170 y ss.

111 WhatThÉe, S., S., op. cit., p. 170 y ss.

112 Ídem supra.

113 WhatThée, S., op. cit., p. 240 y ss. 


\section{El riesgo real e inminente: ¿qué noción de urgencia y qué exigencia de prueba?}

Finalmente, el TEDH alude a la necesidad de que el riesgo que enfrenta el solicitante sea real e inminente en su jurisprudencia referida a la adopción de medidas cautelares. El carácter inminente o urgente de la situación es consustancial a la propia idea de medidas cautelares, tal y como demuestra claramente el ágil procedimiento por el que el TEDH se pronuncia sobre las mismas. Si no existe tal urgencia, el asunto podrá esperar hasta la resolución judicial de fondo, de modo que las cautelares devendrán innecesarias, como ocurre, por ejemplo, en todos aquellos tristes, pero frecuentes, casos en que la víctima de la vulneración de derechos acude a Estrasburgo una vez que el daño se ha materializado, con la única posible intención de obtener algún tipo de indemnización o reparación.

No obstante, la inminencia del riesgo no puede asociarse únicamente al carácter futuro del daño que se prevé. Ese daño ha de ser susceptible de materializarse en un tiempo más o menos breve, lo que no ocurrirá, por ejemplo, si el demandante puede todavía presentar recursos ante las autoridades nacionales que sean suspensivos, o si no se ha adoptado —o se aproxima — la decisión definitiva interna que permitiría la materialización del daño.

Más allá de la urgencia, el riesgo deberá ser real o plausible, en palabras del TEDH ${ }^{114}$, y, por tanto, el solicitante de la medida cautelar deberá presentar prima facie un caso que permita un pronunciamiento en positivo del tribunal, lo que nos reconduce al problema probatorio. Siguiendo las palabras del TEDH y teniendo en cuenta que la Guía práctica sobre las medidas cautelares elaborada por el propio Tribunal recomienda a los solicitantes de las mismas acompañar su petición de todos los documentos necesarios para fundamentarla ${ }^{115}$, parece que podemos afirmar que es el solicitante, al menos en primera instancia, el que tiene la carga de probar que concurren los requisitos para la adopción de la medida cautelar. A pesar de ello, varios autores señalan que el TEDH se esfuerza por comprobar de oficio los hechos alegados por el demandante, especialmente en aquellos casos en que el tiempo apremia ${ }^{116}$.

El TEDH no parece, en buena lógica, exigir prueba plena de los hechos alegados, en la medida en que viene afirmando de forma recurrente que, dadas las características de las medidas cautelares y la necesidad de pronunciarse sobre las mismas en tiempos extraordinariamente breves, los hechos completos del caso no estarán determinados en el momento en que se produzca su pronunciamiento, pudiendo sufrir modificaciones en momentos ulteriores del procedimiento ${ }^{117}$. Parece exigirse, por tanto, tan sólo un indicio de prueba que haga plausible el riesgo alegado por el demandante.

Queda por ver, claro está, sobre qué ha de versar ese indicio de prueba. Teniendo en cuenta los elementos que analiza el TEDH en su juicio sobre las medidas cautelares,

114 Ver, entre otras, STEDH Mannai c. Italia, de 27 de marzo de 2012, § 50, en que se hace referencia al carácter plausible del riesgo, y STEDH Makharadze y Sikharulidze c. Georgia, de 22 de noviembre de 2011, §99, en que se habla de riesgo real.

115 Practice Directions, Request for interim measures, cit. supra, aptdo. I.

116 Morte Gómez, C., op. cit, p. 212-213.

117 Entre otras, ver, STEDH Paladi c. Moldavia, Gran Sala, de 10 de marzo de 2009, § 89. 
parecería sensato pensar que la prueba aportada deberá referirse a todos los elementos que han de concurrir para su adopción, esto es, no sólo deberá permitir al tribunal valorar si los hechos encajan en el contenido de alguno de los derechos reconocidos en el CEDH, sino también si es plausible la existencia de un riesgo inminente de daño grave e irreparable que afecte a unos de esos derechos. Sin embargo, la ausencia de datos detallados sobre los elementos probatorios con los que cuenta el TEDH a la hora de pronunciarse sobre cada medida cautelar impiden realizar cualquier afirmación tajante sobre esta cuestión.

\section{CONCLUSIONES}

La introducción a este texto resaltaba la interrelación evidente entre la tutela cautelar, la adecuada garantía de los derechos de las partes en litigio y el correcto desarrollo de la función de juzgar. Como explicara Calamandrei, las medidas cautelares anticipan provisionalmente algunos efectos de la decisión definitiva a fin de prevenir el daño que podría derivarse del retraso de la misma. Sin ellas, la resolución judicial definitiva puede convertirse en letra muerta y la función del juez en una mera declaración de intenciones.

El TEDH ha reiterado hasta la saciedad su clara intención de proteger derechos reales y efectivos y no teóricos e ilusorios y, en la búsqueda de ese objetivo, una adecuada comprensión de la justicia cautelar parece más que necesaria. En esa lógica, este trabajo ha analizado los tres elementos que se entiende son esenciales para que podamos hablar de una tutela cautelar adecuada, véase, la agilidad en el procedimiento de tramitación y en la adopción de decisiones sobre las medidas cautelares solicitadas, su cumplimiento diligente, y su adopción en aquellos casos en que la negativa generaría situaciones irreversibles, poniendo en riesgo el objeto del proceso y la garantía efectiva de los derechos de las partes.

El análisis de la práctica y la jurisprudencia del TEDH en relación con el procedimiento utilizado por el tribunal para adoptar decisiones en la materia, así como con la obligatoriedad de estas medidas y las obligaciones que al respecto incumben a los Estados parte es más que positiva. El TEDH ha arbitrado un procedimiento diligente, que abandona buena parte de los requerimientos de su procedimiento ordinario, con miras a garantizar el temprano planteamiento de las solicitudes de medidas cautelares y su diligente respuesta por parte del tribunal. Otro tanto puede decirse en relación con la jurisprudencia del TEDH referida a las obligaciones que asumen los Estados parte del CEDH en materia de justicia cautelar: el TEDH ha dejado meridianamente clara la obligatoriedad de sus medidas y ha perfilado de forma nítida y exigente el alcance de los deberes asumidos por los Estados. Éstos deben garantizar el objetivo perseguido por la medida más allá de su interpretación literal, actuar de forma extraordinariamente ágil para darle cumplimiento y organizarse internamente de una forma adecuada para que el mandato del TEDH llegue a la mayor brevedad a quien debe ejecutarlo.

Sin embargo, hay que reseñar que la jurisprudencia del TEDH parece menos garantista en lo que se refiere a la determinación de los elementos a tener en cuenta a la hora de decidir sobre la adopción de una medida cautelar. En su juicio cautelar, el TEDH valora que exista relación con un riesgo real e inminente de que se produzca un daño grave e irreversible en relación con uno de los derechos reconocidos por el CEDH. Esos dos últimos elementos parecen haber sido interpretados por el TEDH de forma un tanto 
restrictiva, en la medida en que la gravedad del daño parece haberse asociado con la posible vulneración de algunos — no todos- derechos del Convenio, y el carácter irreparable del mismo con eventuales consecuencias definitivas. Ambos criterios parecen cuestionables: el primero porque establece una suerte de jerarquía entre los derechos del CEDH que no encuentra justificación alguna — cómo justificar que el derecho a la vida privada y familiar es más relevante que la libertad personal, por poner un ejemplo_-; el segundo, porque obvia que algunos daños temporales pueden ser difícilmente reparados — pensemos en familias que pueden pasar años separadas esperando una resolución sobre el fondo de su caso- - y que las medidas cautelares no han de servir sólo para garantizar el objeto del proceso, sino también los derechos de las partes.

En fin, aún con estas objeciones, parece evidente que, en los últimos años, el TEDH ha desarrollado una tarea titánica en materia de tutela cautelar, tarea que podrá continuar de forma mucho más solvente, a entender de quien suscribe, si perfila en mayor medida los criterios que le sirven de base para conceder o denegar medidas cautelares.

$$
* * * *
$$
case-law

TITLE: Taking interim relief seriously?: Precautionary measures in the European Court of Human Right's

ABSTRACT: Interim relief pursues a vital role as its purpose is not only to enable an effective examination of the case at hand, but also to ensure that the protection afforded to the claimant is effective. In order to achieve those aims, interim measures need to be adopted in a very short period of time and when the claimant faces an irreparable harm. In the last years, interim relief has become a distinctive feature of the European System of Human Rights. Thus, the purpose of this paper is to evaluate the European Court of Human Right's practice and case - law in order to determine whether it is truly guaranteeing rights that are real and effective through its interim measures.

RESUMEN: La justicia cautelar debe permitir a todo tribunal garantizar de forma provisional los derechos de las partes, evitando situaciones irreversibles que puedan convertir en papel mojado su decisión final sobre el fondo del litigio. Para alcanzar esos objetivos, la tutela cautelar debe ser ágil y ha de concederse en todos aquellos casos en los que el daño pueda devenir irreversible. En los últimos años, la tutela cautelar de los derechos reconocidos en el Convenio Europeo de Derechos Humanos se ba convertido en uno de los buques insignia del sistema europeo de protección de los derecbos fundamentales. El objetivo de este trabajo es valorar la práctica y la jurisprudencia en la materia del Tribunal Europeo de Derechos Humanos a fin de determinar si estamos ante una justicia cautelar efectiva, que garantice derechos reales y no teóricos e ilusorios.

KEY WORDS: European Convention on Human Rights; European Court of Human Rights: interim measures.

PalabRAS CLAVE: Convenio Europeo de Derechos Humanos, Tribunal Europeo de Derechos Humanos, medidas cautelares.

FECHA DE RECEPCIÓN: 15.05.2018 FECHA DE ACEPTACIÓN: 13.09.2018 
